\title{
Co-evolutionary Growth: A System Dynamics Model
}

\author{
Fulvio Castellacci \\ University of Oslo \\ E-mail address: fulvio.castellacci@tik.uio.no \\ Phone: +47-22841628
}

Economic Modelling, 2018, forthcoming

\begin{abstract}
The paper presents a new modeling approach for the study of co-evolutionary economic growth. The system dynamics model studies the interactions between four main dimensions: physical capital, $R \& D$ and innovation, human capital, and population dynamics. These factors interact with each other in a complex manner, leading to coevolutionary growth of the economic system. The model generates nonlinearities and multiple growth trajectories, determined by countries' structural characteristics and policy parameters. Developing economies that are able to activate and support synergies among their main growth engines can achieve a faster catch up process and more sustained income per capita level in the long-run than countries characterized by weak co-evolutionary dynamics.
\end{abstract}

JEL: C6; H5; 01; 03; 04

Keywords: Co-evolution; system dynamics; simulation analysis; multiple equilibria; nonlinear growth 


\section{Introduction}

Economic development is a multidimensional process: several factors contribute to explain economic growth and transformations in the long-run. Most scholars interested in growth theory would arguably agree with this statement. However, the field of economic growth has so far developed in a fragmented way, in which different approaches and schools of thought have pointed out the relevance of different growth engines, each focusing on one dimension and often neglecting the others.

Typical examples are the influential model strands focusing on physical capital accumulation (Solow, 1956), human capital (Lucas, 1988; Benhabib and Spiegel, 1994), and R\&D-driven growth (Romer, 1990; Aghion and Howitt, 1992). The reason for this is clear enough: by focusing on one or few important factors and neglecting the others, a growth model can be analytically tractable, and so it is able to provide a thorough analysis of its steady-state properties. Each new growth model describes a subset of relevant mechanisms that were previously unknown in the literature, thus pushing forward the scientific knowledge in this field.

A drawback of this research strategy, though, is that it neglects the study of the interactions among the various growth engines highlighted by different modeling strands. Economic growth is a co-evolutionary process: several factors co-evolve over time in a complex manner. How can we model such a complex co-evolutionary process? Some multiple equilibria models have studied the interactions among different growth factors. Notable examples are multiple equilibria models based on the dynamic interaction between human capital accumulation and technological change (Galor and Moav, 2000; Howitt, 2000; Howitt and Mayer-Foulkes, 2005), new product developments and industrial structure (Kelly, 2001; Hausman and Hidalgo, 2011), population and human capital dynamics (Galor and Weil, 2000; Galor, 2005) or social 
capital and trust (Growieca and Growieca, 2014). In a nutshell, these models show how dynamic feedback effects among two or more variables can generate rapid growth for some developing economies and sluggish performance for others, and so explain the existence of multiple steady states and convergence clubs.

Related to this strand of research, this paper presents a new modeling approach for the study of co-evolutionary economic growth. We build up a comprehensive growth model that, instead of focusing on one or few growth engines, considers together some of the major growth factors previously studied in growth theory: physical capital accumulation, R\&D and innovation, human capital, and population dynamics. The model studies the complex interactions and co-evolutionary process that link these factors together.

In order to simultaneously take into account these factors and their interactions, we make use of a system dynamics modelling approach (Forrester 1961; Sterman, 2002; Booth Sweeney and Meadows, 2010). System dynamics (SD) models are well-suited to study co-evolutionary processes, since they focus on the complex set of feedback mechanisms - or causal loops - that describe the interaction between the relevant variables in the system (Barlas, 1996). Emphasizing the importance of feedback effects in dynamic and complex systems, SD modelling represents an appealing approach to investigate co-evolutionary economic growth, which is indeed driven by the interactions between several related factors such as capital accumulation, $R \& D$ and innovation, and population dynamics.

Specifically, the model that we present in this paper aims at representing the evolution of national economies as driven by the interactions among four distinct growth engines: (1) production and physical capital accumulation; (2) R\&D and innovative activities; (3) education and human capital formation; (4) health and population dynamics. The key 
novelty of this exercise is that, while most previous studies in this field have typically focused on one of these dimensions at a time and neglected the others, our SD model considers them simultaneously and studies the dynamic interactions among them. The simulation analysis shows that the model determines multiple steady states depending on countries' structural characteristics and their set of policy parameters. Specifically, we simulate three distinct growth trajectories: a growth disaster country, which does not experience any visible improvement in its income per capita level over time; a middleincome trapped economy, which grows steadily and slowly, but its transitional dynamics process is long and does not enable to catch up with advanced countries at the frontier; and a growth miracle country, which grows rapidly following a nonlinear trend and completes its catch up process by reaching its steady state level in a relatively short period.

The contribution of this work is to propose SD modelling as a brand new approach to study co-evolutionary economic growth. The main advantage of this approach is its comprehensiveness, i.e. its endeavor to study economic development as a complex process driven by the co-evolution of a multiplicity of variables (Castellacci and Natera, 2013).

The paper is organized as follows. Section 2 briefly summarizes extant literature on coevolutionary growth, and it presents the main ideas and building blocks of the SD modelling approach. Sections 3.1 to 3.4 present the four main sections of the model: (1) production sector and physical capital accumulation; (2) R\&D sector and innovation; (3) education sector and human capital; (4) health sector and population dynamics. Section 3.5 presents an overview of the model and a summary of the main co-evolutionary mechanisms. Section 4 discusses the simulation results and long-run properties of the 
model. Section 5 concludes by discussing the main advantages and possible limitations of the use of system dynamics modeling in growth theory.

\section{Background and approach}

\subsection{Co-evolutionary growth}

While the concept of co-evolution has been studied in biology and natural sciences for a long time already, its use in the social sciences is relatively recent, and its application in economics is still rather limited. In general terms, co-evolutionary growth arises when the dynamics of a system is driven by the growth and mutual interactions between two or more variables (Winder et al., 2005). The idea of co-evolution has in the last few years been used to investigate a variety of different topics broadly related to the fields of economics, business and management studies.

For instance, there are several relevant works that illustrate the use of this approach within the field of innovation and industrial dynamics. Geels (2006) is a seminal study of the emergence and diffusion of new technological paradigms and industries. Windrum and Birchenhall (1998) studied a model of dominant designs and the emergence of market niches. Hacklin et al. (2009) and Robinson (2009) investigated co-evolutionary processes that explain the emergence and diffusion of ICTS and nanotechnologies, respectively. Rios-Nuñez et al. (2013) studied co-evolutionary changes in Spanish livestock; and Quitzow (2015) focused on the case of solar photovoltaics in China and Germany.

Other applications of co-evolutionary theory have focused on the aggregate level of national economies, and studied national systems of innovation and economic development (Sotarauta and Srinivas, 2006). Tsai et al. (2009) pointed out the role of business incubation and national innovation systems in Taiwan. Wong (2011) studied 
the co-evolution of industrial policies and national innovation systems in Southeast Asian economies. Castellacci and Natera (2013) presented a panel cointegration study of the co-evolution between innovative capability and absorptive capacity in national innovation systems. More recently, García-Cabrera and Duran-Herrera (2016) studied the interplay between institutions and multinational enterprises.

Other works have applied the concept of co-evolutionary growth to study firm-level and organizational dynamics. Reid and Smith (2009) studied information system dynamics in small entrepreneurial firms. Abatecola (2012) focused on corporate crises and suggested to explain them as the co-evolution of managerial and environmental factors. Hynes and Wilson (2012) studied the formation of strategic alliances between firms along the industry life cycle. And Luo et al. (2014) presented a microfounded model of knowledge diffusion and social network structure.

\subsection{The system dynamics modelling approach}

Although the studies noted in the previous section investigate a variety of different topics, what they have in common is the focus on the dynamic and feedback nature of co-evolutionary growth, in which several variables interact with each other driving the growth of the system. The focus on the dynamic and feedback nature of a system is precisely the typical feature of a system dynamics modelling approach (Barlas, 1996).

System dynamics (SD) is a modeling methodology that studies the dynamic interactions and feedback effects among a set of variables that compose a system (Forrester 1961; Sterman, 2002; Booth Sweeney and Meadows, 2010). ${ }^{1}$ Variables are conceptualized as

\footnotetext{
${ }^{1}$ Recent examples of applications of the SD approach are for instance Castellacci and Hamza's (2015) study of policy strategies for development, and Feng et al.'s (2016) study of water supply and environmental systems.
} 
stocks, with inflows and outflows that determine the value of each stock variable at a given time, and information flows that connect the various stock variables together.

A SD model is driven by several feedback mechanisms interlinked with each other. Each feedback mechanism - or causal loop - describes the interaction between two (or more) variables in the system. A feedback can lead either to a reinforcing loop, in which the dynamics of two variables support each other, or to a balancing loop, in which one variable attenuates the growth of the other and brings it back to its equilibrium path. The whole set of causal loops determines the dynamics of the system over time. A typical way to represent and visualize causal loops in SD models is the so-called causal loop diagram, which consists of a set of nodes and edges. Nodes are the variables composing the system, and edges are arrows representing the causal relationships among these variables (Barlas, 1996; Sterman, 2002).

Mathematically, a system dynamics model is represented as a set of ordinary nonlinear integral equations. Since it is typically not possible to obtain mathematically analytical solutions and dynamic equilibrium conditions for this type of system, system dynamics models make use of computer simulations to analyze its dynamic behavior and time trends.

Forrester (1979), Barlas (1996) and Sterman (2002) discuss model validation and analysis in the SD approach. In short, SD model analysis consists of two phases. One is to carry out computer simulations to perform a sensitivity analysis, which is important to understand "why the model behaves the way it does" (Barlas, 1996), and the dynamic outcomes it leads to over time. The second is to carry out simulations to perform a policy analysis, in which the analyst studies the extent to which model's outcomes vary if different policy actions are introduced (e.g. the "changed-behavior-prediction" test; see Forrester, 1979). The next section will present our SD model to analyze co-evolutionary 
dynamics in economic growth, and the subsequent section will then analyze the model's properties and results as customary in the SD approach.

\section{A system dynamics model of co-evolutionary economic growth}

Our SD model of economic growth has an intricate structure. It comprises around 80 variables that endogenously evolve over time, and nearly 40 parameters that represent (exogenous) structural characteristics of the economy. This section presents the mathematical formulation of the model. The Appendix reported at the end of the paper lists for convenience all the variables and parameters of the model.

The model aims at representing the evolution of national economies as driven by the interactions among different growth engines. The economy is composed of four main sectors interacting with each other: (1) production; (2) R\&D; (3) education; (4) health. These four sectors focus on the major engines of economic development that have traditionally been investigated by the economic growth literature, and more recently by multiple equilibria models: physical capital accumulation; innovation; human capital accumulation; population. The key novelty of our exercise is that, while most previous studies in this field have typically focused on one of these dimensions at a time and neglected the others, our SD model considers them simultaneously and studies the dynamic interactions among them.

There are three industries in the economy: agriculture, manufacturing and services. The total GDP of the country at time $t$ is:

$\operatorname{GDP}(t)=\sum_{j} \operatorname{GDP}(j ; t)$ 
where $j$ indicates the industry. The country's GDP is composed of two parts: private and public GDP. The private sector GDP is:

$\mathrm{PGDP}=\Omega \bullet \mathrm{GDP}(t)$

where $\Omega$ denotes the private sector share of GDP $(0<\Omega<1)$. Total government expenditures (the public component of GDP) are:

$\mathrm{GOV}=\Psi \cdot \operatorname{GDP}(t)$

where $\Psi$ indicates the public sector share of GDP $(0<\Psi<1 ; \Psi+\Omega=1)$.

Public GDP is allocated among different types of public expenditures:

$\mathrm{GOV}=\mathrm{GINV}(t)+\mathrm{GR} \& \mathrm{D}(t)+\mathrm{GEB}(t)+\mathrm{GHB}(t)+\mathrm{GOTH}(t)$

where the first four components refer to the different sectors of the model: public investments in infrastructure (GINV), public R\&D (GR\&D), education and human capital investments (GEB), and public health services (GHB). The fifth term GOTH( $t$ ) indicates public expenditures on all other activities not considered in the model (e.g. defence, social issues, cultural activities; Zagler and Durnecker, 2003).

\subsection{Production sector and physical capital accumulation}

The accumulation of physical capital is one of the central factors traditionally highlighted in mainstream economic growth theory (Solow, 1956). In our SD model, there are three distinct sources of physical capital investments: domestic firms' private 
investments, foreign multinational enterprises' (MNEs) inward foreign direct investments (FDI), and public investments to develop the country's physical infrastructures.

The stock of physical capital accumulated by private firms at time $t$ equals the capital stock in the previous period plus the new investments undertaken in period $t:^{2}$

$\operatorname{PK}(t)=\operatorname{PK}(t-d t)+\int\left[\pi \cdot \operatorname{PGDP}(t)-\frac{\mathrm{PK}(t)}{\rho}\right] d t$

The new investments undertaken in the period (the integral term in equation 5) is the sum of all new investments carried out by the domestic private sector (the parameter $\pi$ denotes the share of private sector GDP that is reinvested in the economy) minus a capital depreciation term that depends on the average lifetime of capital $\rho$.

Secondly, the stock of inward foreign direct investments at time $t$ is given by the FDI stock in the previous period plus all new inward FDI carried out by foreign MNEs in the country:

$\operatorname{FDI}(t)=\operatorname{FDI}(t-d t)+\int\left[\mathrm{p} \cdot \operatorname{GDP}(t)-\frac{F D I(t)}{\rho}\right] d t$

The parameter $\mathrm{p}$ defines the rate at which new FDI investments are undertaken at any time $t$, and FDI capital accumulation is also subject to a capital depreciation term related to the obsolescence parameter $\rho$. Inward FDI are undertaken in the three industries of the economy at a different rate:

\footnotetext{
${ }^{2}$ The integral in equation 6 , and all other integrals noted in the following equations, are defined in the interval $(t-d t)$ to $t$.
} 
where we assume for simplicity that the rate of inward FDI in a given industry is proportional to the industry's share of GDP $\Pi(j$ ) (defined further below), representing the idea that foreign MNEs will invest more in those sectors of the economy in which the country is specialized and has a higher infrastructure pool and resource endowment (reflected in its GDP share).

Thirdly, capital accumulation is also fostered by public sector investments that seek to improve the country's physical infrastructures. Public infrastructural investments are defined as:

$\operatorname{GINV}(t)=\varsigma \cdot \operatorname{GOV}(t)$

where the parameter $\varsigma$ denotes the share of public expenditures GOV that is allocated to infrastructures every year. Public investments are allocated among the three industries according to the parameter $\sigma(j)$, which indicates the share of GINV that is invested in sector $j$, with $\sum_{j} \sigma(j)=1$.

The total physical capital stock accumulated at time $t$ is in each industry $j$ is the sum of the sectoral capital stock in the previous period, plus all new capital investments from the three sources noted above (private investments, inward FDI and public infrastructures), minus a capital depreciation term (for simplicity assumed the same across the three industries):

$$
\mathrm{K}(j ; t)=\mathrm{K}(j ; t-d t)+\int\left[\sigma(j) \bullet \operatorname{GINV}(t)+\pi \bullet \operatorname{PGDP}(j ; t)+\mathrm{FDI}(j ; t)-\frac{\mathrm{K}(j ; t)}{\rho}\right] d t
$$


Physical capital investments drive the growth of the economy through two distinct channels: one is embodied technological progress, and the other is structural change. First, capital investments increase directly sectoral labor productivity: in each industry, a greater stock of physical capital and a better quality of public infrastructures enable domestic companies to increase their productivity over time (embodied technological progress). Specifically, we assume that the labor productivity of industry $j$ grows over time as the product of three components: the total capital invested in the industry $\mathrm{K}(j ; t)$, the education level of its workforce $\operatorname{EDU}(t)$ and its innovative capability IC $(j ; t) .{ }^{3}$ The multiplicative function represents the idea that sectoral productivity grows as a function of the interaction between capital investments, human capital and innovation. i.e. it is the synergies between these three important growth engines that drive productivity dynamics (Castellacci, 2011). ${ }^{4}$ The productivity growth is:

$$
\mathrm{LP}(j ; t)=\mathrm{LP}(j ; t-d t) \cdot\left[\frac{d}{1+\mathrm{e}^{-\mathrm{K}(j ; t)}} \cdot \frac{e}{1+\mathrm{e}^{-\mathrm{EDU}(t)}} \cdot \frac{f}{1+\mathrm{e}^{-\mathrm{IC}(j ; t)}}\right]
$$

All three terms in square brackets on the RHS of equation 10 assume a logistic link between sectoral productivity, on the one hand, and physical capital, human capital and innovation, on the other. The logistic function formalizes the idea that as the processes of capital accumulation and R\&D capability building unfold, the productivity of labor will

\footnotetext{
${ }^{3}$ The education level of the workforce $(\operatorname{EDU}(t)$ is defined as the ratio between the number of persons with a tertiary degree, $\operatorname{TER}(t)$, and the total population workforce, POPW $(t)$; see section 3.3. The innovative capability term IC $(t)$ will be further specified in section 3.2.

${ }^{4}$ As pointed out by Barlas (1996), multiplicative functions in system dynamics modelling have two important characteristics. The first is that zero values of any of the input variables will dominate the outcome variable regardless of the values of the other input variables. In equation 10 this means that, for labor productivity to have positive growth, all three variables physical capital, human capital and innovation must have positive values, emphasizing the multi-dimensional nature of productivity growth. The second characteristic is that, given that effects are multiplied, the joint effect will increase geometrically. In equation 10, this second characteristic of the multiplicative formulation points out the relevance of interaction and synergy effects among physical capital, human capital and innovation for the growth of sectoral productivity.
} 
initially grow slowly, then peak up after a given threshold level, and eventually slow down due to diminishing returns and settle around a maximum level given by the product of the three parameters $d, e$ and $f$ (which represent the carrying capacity parameters of the three logistic curves). ${ }^{5}$ Hence, at any given time $t$, labor productivity will grow at a rate defined by the three terms in square brackets in equation 10 .

Secondly, physical capital accumulation triggers a process of industrial transformation (structural change) according to which workers tend to shift from traditional and lowskill jobs in the primary sector towards more technologically advanced and higherproductivity activities in secondary and tertiary branches. Specifically, our model assumes that workers decide their sector of occupation based on an attractiveness variable, which is a function of the share of physical capital (infrastructures) that is invested at any time $t$ in each of the three industries: ${ }^{6}$

$\operatorname{ATTR}(j ; t)=\frac{\mathrm{K}(j ; t)}{\sum_{j} \mathrm{~K}(j ; t)}$

The amount of labor employed in industry $j$ can then be defined as:

$\mathrm{L}(j ; t)=\operatorname{POPWA}(t) \cdot \operatorname{ATTR}(j ; t-s)$

where $\operatorname{POPW}^{\mathrm{A}}(t)$ is the economically active working age population (defined in section 3.4), and $s$ is the time that it takes for the attractiveness level to affect the sectoral labor

\footnotetext{
${ }^{5}$ The idea that productivity growth follows a logistic path was previously put forward in the models of Carlaw and Lipsey (2006) and Castellacci (2010). Empirical evidence in support of the logistic functional form to model productivity dynamics was presented by Castellacci (2004).

${ }^{6}$ The underlying idea is that sectors with high capital investments are those that face more dynamic technological opportunities and market demand, and that also tend to present more attractive conditions for workers (e.g. in terms of new employment opportunities and rising wage level).
} 
share (since we assume that the shift of workers from primary to secondary and tertiary activities takes time to unfold). The labor share of industry $j$ is therefore:

$\mathrm{LS}(j ; t)=\frac{\mathrm{L}(j)}{\operatorname{POPWA}(t)}$

The basic idea of this structural change mechanism is that as the economy develops, capital investments and infrastructure building in manufacturing and service industries will grow relatively faster than capital accumulation in the agriculture sector, and so workers would gradually shift from primary to secondary and tertiary branches.

Given the sectoral employment and productivity levels, the total GDP produced by industry $j$ is:

$\mathrm{GDP}(j ; t)=\mathrm{L}(j ; t) \cdot \mathrm{LP}(j ; t)$

We then assume that a part $\mathrm{C}(j ; t)$ of each industry's GDP(j;t) is consumed by the country's population:

$\mathrm{C}(j ; t)=\tau(j) \cdot \mathrm{GDP}(j ; t)$

The parameter $\tau(j)$ thus denotes the fraction of GDP that is consumed by households to purchase goods produced by industry $j$. Finally, we define the net export of industry $j$ as:

$\operatorname{EXP}(j ; t)=\operatorname{GDP}(j ; t)-\mathrm{C}(j ; t)$ 
If sectoral GDP is greater than domestic demand (GDP(j;t)>C(j;t)), then industry $j$ is a net exporter $(\operatorname{EXP}(j ; t)>0)$. By contrast, if sectoral GDP is lower than domestic demand $(\mathrm{GDP}(j ; t)<\mathrm{C}(j ; t))$, the country must import the quantity of goods and services that is not available domestically, and industry $j$ will then be a net importer $(\operatorname{EXP}(j ; t)<0)$.

\subsection{R\&D sector and innovation}

The creation of new technologies is the main engine of economic development according to models of innovation and economic growth, both within new growth theory and in the evolutionary economics tradition (Nelson and Winter, 1982; Romer, 1990; Aghion and Howitt, 1992). In line with this literature, our SD model points out R\&D and innovation as key factors driving the dynamics of the economic system, but it also emphasizes the interactions that science and technology (S\&T) variables have with the rest of the economic system. We assume that innovation is jointly determined by the interaction of two components: basic research and scientific activities carried out by public research organizations, and applied R\&D projects undertaken by private business companies (Castellacci and Natera, 2013).

We first model basic research and scientific activities. These are carried out by public research organizations (Universities and public research institutes) by using two main inputs: public resources allocated in each annual Government budget to R\&D activities, and advanced human capital that is employed in this sector (i.e. PhD graduates that are employed in public R\&D organizations). We argue that the larger the pool of advanced human capital that is publicly employed, the higher will be the productivity of scientific research. The overall scientific output produced by the country during each year (e.g. measured through the number of published scientific articles) will therefore be a 
positive function of the amount of public resources invested in the sector as well as its productivity.

Public resources allocated in each annual Government budget to R\&D activities are:

$\operatorname{GR} \& D(t)=v \cdot \operatorname{GOV}(t)$

where $v$ is the share of Government expenditure (GOV) assigned to public R\&D. The allocation of public R\&D investments among the three industrial sectors of the economy is defined by the country's priorities in terms of science and innovation policy, and can be summarized as:

$\mathrm{GR} \& \mathrm{D}(j ; t)=\varphi(j) \cdot \mathrm{GR} \& \mathrm{D}(t)$

which indicates that public R\&D investments in sector $j$ represent a fraction $\varphi(j)$ of total public R\&D investments (with $\sum j \varphi(j)=1$ ).

These public resources are used by scientists to finance their labor costs. We assume for simplicity that all scientists employed in the public R\&D sector have a PhD degree. The number of PhD graduates employed in public sector research at any time $t$ is defined by the expression:

$\operatorname{GPHD}(t)=\operatorname{GPHD}(t-d t)+\int\left[\frac{\operatorname{GR} \& D(t)-\psi \operatorname{GPHD}(t)}{\psi}-\omega \operatorname{GPHD}(t)-\operatorname{GPHD}(t) \cdot \operatorname{FDR}(t)\right] d t$

Equation 18 points out that the stock of scientists at time $t$ is the sum of researchers in the previous period plus the newly hired researchers in period $t$ (given the labor cost $\psi$ ), 
minus the number of senior researchers that retire (according to the retirement rate $\omega$ ), minus the number of researchers employed in the public sector that die (according to the fractional death rate FDR, defined in section 2.4 below). The number of PhD graduates employed in public sector research in field $j$ is defined as:

$\operatorname{GPHD}(j ; t)=\ddot{v}(j) \bullet \operatorname{GPHD}(t)$

where $\ddot{v}(j)$ is the fraction of publicly employed $\mathrm{PhD}$ that works in field $j$ (with $\sum_{j} \ddot{\mathrm{u}}(j)=$ 1). ${ }^{7}$

The productivity of the public research sector in each field $j$ - or scientific output productivity $\operatorname{SOP}(j ; t)$ - is given by the function:

$\operatorname{SOP}(j ; t)=\operatorname{SOP}(j ; t-d t) \cdot \log [\mathrm{GPHD}(j ; t)]$

This formulation argues that scientific productivity in a given field (industrial sector) $j$ grows over time as a logarithmic function of the number of $\mathrm{PhD}$ graduates employed in in that field. The log link represents the idea that an increase in the stock of researchers does initially have a strong effect on the growth of the country's scientific productivity; but the marginal effect of the expansion of the public research sector will tend to be progressively weaker at later stages of the growth process. The logistic link put forward here is based on the same idea of productivity dynamics noted in equation 10 above. As previously noted, this assumption is based and empirically corroborated by previous

\footnotetext{
${ }^{7}$ For simplicity, we assume a one-to-one correspondence between industrial sectors and scientific fields, and hence use the same index $j$ for both. In other words, in this model researchers are employed either in agriculture-related fields, or in manufacturing- or service-related fields.
} 
models on innovation and economic growth (Carlaw and Lipsey, 2006; Castellacci, 2004 and 2010).

Given the amount of resources employed in public research at any given time $t$ and its productivity level, the total scientific output produced annually in field $j$ is defined as:

$\mathrm{SO}(j ; t)=\mathrm{SO}(j ; t-d t)+\int\left[\mathrm{GR} \& \mathrm{D}(j ; t) \cdot \mathrm{SOP}(t-r)-\frac{\mathrm{SO}(j ; t)}{\chi}\right] d t$

Equation 21 points out that scientific output grows every year due to the new publications produced in the period (where $r$ is a lag between R\&D investments and scientific output); but the growth of the scientific stock is also constrained by a depreciation factor, which is defined by the parameter $\chi$ indicating the average lifetime of scientific output.

The other dimension of the R\&D sector is represented by applied R\&D projects carried out by private profit-motivated firms. Technological R\&D investments undertaken by private companies also use two types of inputs: financial resources that firms invest in $\mathrm{R} \& \mathrm{D}$, and skilled human capital (i.e. researchers employed in the private sector). The latter factor enhances the productivity of applied research in the business sector.

The amount of private R\&D investments in industry $j$ is:

$\operatorname{PR} \& D(j ; t)=\operatorname{PGDP} \bullet \Theta(j)$

where PGDP is private sector GDP and the sector-specific parameter $\Theta(j)$ denotes the share of private sector GDP allocated to R\&D in that industry. Hence, the total amount of private $R \& D$ investments in the country is the sum of $R \& D$ expenditures in the three industrial sectors: $\mathrm{PR} \& \mathrm{D}(t)=\sum_{j} \mathrm{PR} \& \mathrm{D}(j ; t)$. 
The stock of researchers with a PhD degree that are employed in private sector research at time $t$ is given by the expression:

$\operatorname{PPHD}(t)=\operatorname{PPHD}(t-d t)+\int\left[\frac{\operatorname{PR\& D}(t)-\Gamma \cdot \operatorname{PPHD}(t)}{\Gamma}-\omega \bullet \operatorname{PPHD}(t)-\operatorname{PPHD}(t) \cdot \operatorname{FDR}(t)\right] d t$

Analogously to the definition of the stock of public scientists noted above, equation 23 defines the stock of applied private sector researchers at time $t$ as the sum of researchers in the previous period plus the newly hired researchers in period $t$ (given the labor cost $\Gamma$ ), minus the number of senior researchers that retire (according to the retirement rate $\omega$ ), minus the number of researchers employed in the private sector that die (according to the fractional death rate FDR, defined in section 3.4 below). The number of PhD graduates employed in private sector applied research in field $j$ is thus:

$\operatorname{PPHD}(j ; t)=\Lambda(j) \cdot \operatorname{PPHD}(t)$

where the parameter $\Lambda(j)$ denotes the fraction of privately employed PhD that works in field $j$ (with $\left.\sum_{j} \Lambda(j)=1\right)$.

The productivity of applied research in industry $j$ - or technological output productivity $\operatorname{TOP}_{j}(t)$ - is assumed to grow as a function of the size of the private R\&D sector.

$\mathrm{TOP}(j ; t)=\mathrm{TOP}(j ; t-d t) \cdot \log [\mathrm{PPHD}(j ; t)]$

Similarly to the formulation of scientific productivity dynamics above, the log function in equation 25 points out the idea that an increase in the stock of researchers employed in the private sector does initially have a strong effect on the growth of the country's 
productivity of applied research; but the marginal effect of the expansion of the private R\&D sector will tend to be progressively weaker at later stages of the growth process (Carlaw and Lipsey, 2006).

Given the available stock of advanced human capital employed in applied research in industry $j$ and its productivity level, the technological output in that industry (e.g. measured in terms of the patent stock) can be defined as:

$\mathrm{TO}(j ; t)=\mathrm{TO}(j ; t-d t)+\int\left[\mathrm{PR} \& \mathrm{D}(j ; t) \bullet \operatorname{TOP}(t-r)+\Phi \mathrm{GR} \& \mathrm{D}(j ; t) \operatorname{SOP}(t)-\frac{\mathrm{TO}(j ; t)}{\Xi}\right] d t$

This expression indicates that sectoral technological output (patent stock) grows over time as a function of two factors. On the one hand, it increases because of the new patents produced by private sector researchers in year $t$ in field $j$ (with $r$ denoting the lag between $R \& D$ investments and technological output). On the other, the patent stock also grows because of the effects of scientific activities on technological output, where the parameter $\Phi$ indicates the effects of scientific on technological output. This represents the idea, well-known in the innovation literature, that science and technology are intertwined, and in particular that basic research constitutes an important platform upon which applied R\&D activities unfold (Nelson, 1982). It is then reasonable to formulate a direct link between scientific (basic) research and applied technological activities. Finally, equation 26 also indicates that the dynamics of technological output will also be counteracted by a depreciation factor defined by the average lifetime of technological output $\Xi$.

After having described the functioning of basic and applied R\&D, we can then define two more variables that summarize the dynamics of the R\&D sector, and that we will focus 
on in the model simulation analysis. The first variable is the innovative capability of sector $j$ :

$\operatorname{IC}(j ; t)=\operatorname{IC}(j ; t-d t) \cdot\left[\frac{\mathrm{g}}{1+e^{-\operatorname{SOP}(j ; t)}} \cdot \frac{\mathrm{h}}{1+e^{-\mathrm{TOP}(j ; t)}}\right]$

According to equation 27, sectoral innovative capability grows over time as a function of the product of two terms: scientific and technological productivity. Both of the functions in square brackets on the RHS of equation 27 formulate a logistic link between innovative capability, on the one hand, and scientific and technological productivity, on the other. The logistic function points out the idea that as the productivity of basic and applied research grow over time, sectoral innovative capability will initially grow slowly, then peak up after a given threshold level, and eventually slow down and settle around the ceiling levels $g$ and $h$, respectively. These parameters represent the carrying capacity parameters of the two logistic curves, namely the maximum increase in innovative capability that it is possible to achieve in relation to an increase in scientific and technological productivity (Castellacci, 2004). The multiplicative function in equation 27 represents the idea that sectoral innovative capability grows as a function of the interaction between in scientific and technological productivity. i.e. it is the synergies and reinforcing feedbacks between scientific and technological advances that sustain the sectoral dynamics of innovative capability (Nelson, 1982).

The second variable that summarizes this section of the model is the ratio of science to technological output. In sector $j$, this ratio is given by:

$\operatorname{STR}(j ; t)=\frac{\operatorname{sOP}(j ; t)}{\operatorname{TOP}(j ; t)}$ 
and in the whole economy, it is defined as:

$\operatorname{STR}(t)=\frac{\sum_{j} \operatorname{SOP}(j ; t)}{\sum_{j} \operatorname{TOP}(j ; t)}$

\subsection{Education sector and human capital}

Human capital is another key engine of economic development investigated by a large number of contributions in growth theory (e.g. Lucas, 1988; Benhabib and Spiegel, 1994). In our model, public expenditures on education affect economic growth in two ways. First, public education infrastructures and a good schooling system increase the basic education level of the working population (e.g. measured in terms of literacy rate, primary, secondary or tertiary ratios). This will contribute to enhance the productivity of the supply-side of the economy, and hence further sustain GDP growth and publicly available resources in the future. Secondly, a selected number of tertiary graduates will decide to enroll in $\mathrm{PhD}$ programmes (which may be financed either publicly or privately), and after obtaining their doctoral degree will work as researchers either in the public science system or in private R\&D departments, as described in section 3.2 above. Hence, greater public investments in education will also partly enhance the formation of advanced human capital, which will contribute to the productivity of the $\mathrm{R} \& \mathrm{D}$ sector as noted above.

First, we define the Government's stock of resources allocated to public expenditures in education (GEB) in period $t$ as:

$$
\operatorname{GEB}(t)=\operatorname{GEB}(t-d t)+\int[\kappa \cdot \operatorname{GOV}(t)-\lambda \cdot \operatorname{STU}(t)] d t
$$


The stock GEB grows from one period to the next by means of the new allocation to public expenditures in year $t$ (the parameter $\kappa$ is the share of Government's expenditures (GOV) allocated to public education in the period), and it decreases by an amount equal to the costs incurred to sustain the pool of students STU that are enrolled in the public schooling system at time $t$ (the parameter $\lambda$ measures the amount of public investment required per student).

Students are enrolled in different degrees of the public education system: primary education (STUPRI), secondary education (STUSEC), tertiary education (STUTER), Master (STUMAS) or PhD programmes (STUPHD). So, the total stock of students at time $t$ is:

$\operatorname{STU}(t)=\operatorname{STU} U_{P R I}(t)+\operatorname{STU} U_{S E C}(t)+\operatorname{STU} U_{T E R}(t)+\operatorname{STU} U_{M A S}(t)+\operatorname{STU} U_{P H D}(t)$

In each education phase $i$, the number of enrolled students can be defined as:

$\operatorname{STU}(i ; t)=\operatorname{STU}(i ; t-d t)+\int[\operatorname{ENR}(i ; t)-\operatorname{GRAD}(i ; t)-\operatorname{DROP}(i ; t)] d t$

where: $\operatorname{STU}(i ; t)=\operatorname{STU} \operatorname{PRI}(t) ; \operatorname{STU} \sec (t) ; \operatorname{STU}_{\mathrm{TER}}(t) ; \operatorname{STU} \operatorname{SAs}(t) ; \operatorname{STU} \operatorname{PhD}(t)$. Equation 32 points out that the stock of students in each education phase $i$ grows over time because of new enrolled students $\operatorname{ENR}(i ; t)$, and it decreases by the amount of students who exit that education phase, either because they graduate successfully (GRAD $(i ; t))$ or because they drop out of the education system (DROP $(i ; t))$. The number of new enrolled students is:

$\operatorname{ENR}(i ; t)=\mu(i) \cdot \operatorname{POP}(i ; t)$ 
where $\mu(i)$ defines the country's enrollment rate of population in education phase $i$ $(\mathrm{POP}(i))$. The number of new graduates is:

$\operatorname{GRAD}(i ; t)=v(i) \cdot \operatorname{STU}(i ; t)$

with $v(i)$ denoting the graduation rate of students enrolled in education phase $i$ (POP(i)). Finally, the number of students dropping out of the education system is:

$\operatorname{DROP}(i ; t)=\xi(i) \cdot \operatorname{STU}(i ; t)$

where the parameter $\xi(i)$ indicates the drop-out rate of students enrolled in education phase $i(\mathrm{POP}(i))$. At any time $t$, there is a number of students that have not completed tertiary education:

$\operatorname{NOTER}(t)=\operatorname{NOTER}(t-d t)+\int\left[\sum_{i} \operatorname{DROP}(i ; t)\right] d t$

where $i=$ PRI; SEC; TER. We assume that these young workers can be employed by firms in the production sector like all other graduated students, but they will not contribute to increase the productivity of the industry in which they are employed due to their relatively low education level. By contrast, students that complete their tertiary education will enhance the sectoral labor productivity of the economy (as seen in equation 10 above). The number of skilled workers with completed education level $i$ that are employed in the labor market $\left(\operatorname{SKILL}_{i}(i ; t)\right)$ is: 
$\operatorname{SKILL}(i ; t)=\operatorname{SKILL}(i ; t-d t)+\int[\operatorname{GRAD}(i ; t)-\operatorname{ENR}(i+1 ; t)-\operatorname{RET}(i ; t)-\operatorname{WDR}(t)] d t$

where $i=$ tertiary, Master, PhD. Equation 37 points out that the stock of skilled workers with an advanced education degree in phase $i$ (tertiary, Master or PhD level) grows over time as a positive function of the number of new graduates in that education phase that enter the labor market after graduation, and it decreases because of skilled workers that exit employment activities - either because they decide to enroll in more advanced education level $i+1\left(\left(\operatorname{ENR}_{i+1}(t)\right)\right.$ or because they retire $(\operatorname{RETi}(t))$ or die $(\operatorname{WDR}(t))$. The number of senior skilled workers that retire at any time $t$ is defined as:

$\operatorname{RET}(i ; t)=o(i) \cdot \operatorname{SKILL}(i ; t)$

with o(i) indicating the retirement rate for skilled workers with completed education level $i$ (SKILLi); and the number of skilled workers that exit the labor market because they die is:

$\operatorname{WDR}(t)=\operatorname{POPW}(t) \cdot \operatorname{FDR}(t)$

where the stock of working age population POPW $(t)$ and the fractional death rate $\operatorname{FDR}(t)$ will be defined in section 3.4 below.

\subsection{Health sector and population dynamics}

The dynamics of a country's population is another crucial factor to shape the nation's development path in the long-run. On the one hand, a growing population enhances economic growth by making available a large pool of human resources that can be used 
in production and R\&D activities. On the other hand, however, a smaller population size means that a given level of GDP leads to a higher individual wealth on average (e.g. as measured by the country's GDP per capita). Models of population and economic development have extensively investigated these issues, e.g. by studying changes in fertility decisions along the demographic transition that countries experience along the development process (Galor, and Weil, 2000).

Our SD model provides a simplified view of the population and health sector of the economy. Public expenditures on health infrastructure represent the fourth component of public GDP considered in the model. These improve the country's health infrastructures by renovating depreciated health capital as well as extending public health services. Public health expenditures will in the long-run be able to increase the birth rate, decrease mortality and hence increase the size of the working population, thus fostering economic growth. However, in line with models of the demographic transition, we also argue that as a country grows and become richer, parents will typically choose to have less children, and the average fertility rate in the economy will tend to decrease (Galor, 2005). This second mechanism counteracts the first one and poses a constraint to the growth of the economy in the long run.

We begin by defining the amount of publicly available resources for health expenditures:

$$
\operatorname{GHB}(t)=\operatorname{GHB}(t-d t)+\int[(\alpha \operatorname{GOV}(t))-\beta \mathrm{OHC}(t)-\gamma \mathrm{NHC}(t)] d t
$$

Public health expenditures grow over time by the amount of new financial resources allocated to the health sector by the Government's budget in year $t$ (where $\alpha$ represents the share of $\operatorname{GOV}(t)$ assigned to public health); and it decreases by the amount of costs incurred by the health sector in the period. These costs have two components: one is 
ordinary expenditures for running already existing operating health centres $\mathrm{OHC}(\beta$ denotes the operational costs per health center per year); the other is the amount of resources that it is necessary to build new health centres $\mathrm{NHC}(\gamma$ is the fixed costs to build a new health center).

At any time $t$, the total number of health centres can be expressed as:

$\mathrm{HC}(t)=\mathrm{HC}(t-d t)+\int\left[\mathrm{NHC}(t)-\frac{\mathrm{OHC}(t)}{\delta(t)}\right] d t$

which grows over time because of newly built health facilities (NHC), and decreases due to a depreciation factor defined by the variable $\delta$ (average lifetime of health centres). We further assume that this depreciation factor of health infrastructures is not fixed over time, but it is a non-linear function of the amount of public resources invested in the health sector:

$\delta(t)=\left[\frac{\gamma}{1+e^{-\mathrm{GHB}(t)}}\right]$

Equation 42 points out that the average lifetime of health centres positively depends on the amount of public resources that are invested for their maintenance. Further, we argue that this positive relationship follows a logistic link, representing the idea that public investments can initially lead to a sustained growth of health centres' lifetime; however, beyond a certain threshold level ( $\gamma$, ceiling of the logistic function), further increases in Government expenditures will not have any significant effect on the lifetime of a health facility. 
The quality and functioning of a health centre can be defined in terms of its density. Specifically, we define the variable inverse health density as:

$$
\mathrm{HD}(t)=\frac{\mathrm{PHC} *}{\mathrm{PHC}(t)}
$$

which is the ratio between the desired (optimal) number of people per health center (PHC*) and the effective number of people per health center at a given time $\mathrm{PHC}(t)$; the latter is defined as: $\operatorname{PHC}(t)=\operatorname{POP}(t) / \mathrm{HC}(t)$. When the inverse health density variable is high (low), the country is endowed with a good (poor) health infrastructures in relation to the size of its population.

The outcomes of public health expenditures are then defined in terms of this inverse health density variable. The country's average life expectancy $\operatorname{LE}(t)$ at time $t$ is given by:

$$
\mathrm{LE}(t)=\mathrm{LE}(t-d t) \cdot\left[\frac{\mathrm{a}}{1+e^{-\mathrm{HD}(t)}}\right]
$$

Equation 44 points out a logistic link between the life expectancy of the population and the country's quality of health infrastructures. This is based on the idea that the quality of health infrastructures has initially a substantial positive effect on the country's health outcomes; however, this positive impact becomes progressively smaller, faces decreasing returns and then eventually stops at the level $a$ (which is a parameter representing the max increase in life expectancy that can be achieved by improving health infrastructures, and which is determined by exogenous biological factors). We then define the fractional death rate $\operatorname{FDR}(t)$ as a negative function of the inverse health density: 
$\operatorname{FDR}(t)=\operatorname{FDR}(t-d t) \cdot \frac{\mathrm{b}}{\operatorname{HD}(t)}$

where the parameter $b$ is the slope of the effect of health conditions on mortality rate. ${ }^{8}$ Similarly, the fertility rate (fractional birth rate $\operatorname{FBR}(t)$ ) is also assumed to decrease linearly as a function of the quality of health infrastructures (with slope $c$ ):

$\operatorname{FBR}(t)=\operatorname{FBR}(t-d t) \cdot \frac{c}{\operatorname{HD}(t)}$

After having described how public health expenditures affect the country's main health outcomes, it is then easy to define the dynamics of the economy's population. The total population at time $t$ is:

$\operatorname{POP}(t)=\mathrm{POP}(I ; t)+\mathrm{POP}(S ; t)+\mathrm{POPW}(t)+\mathrm{POP}(E ; t)$

where $\operatorname{POP}(I)$ is the infant population, $\mathrm{POP}(S)$ the population in school age, POPW the working age population, and $\operatorname{POP}(E)$ the elderly population. Each of these can be represented in a similar manner as a stock of people that changes over time as the result of inflows and outflows. Specifically, the infant population:

$\operatorname{POP}(I ; t)=\operatorname{POP}(I ; t-d t)+\int[\operatorname{BR}(t)-\operatorname{BSA}(t)-\operatorname{IDR}(t)] d t$

\footnotetext{
${ }^{8}$ For simplicity we assume that the infant fractional death rate is the same as the one for adult population.
} 
grows over time due to the inflow of new births $B R(t)$, and decreases subject to two outflows: the number of children $\operatorname{BSA}(t)$ ("becoming school age") that exit from the infant and enter the school age; and the number of infants that die (IDR). The country's birth rate is defined as:

$\operatorname{BR}(t)=\operatorname{FBR}(t) \cdot \operatorname{PFP}(t)$

where $\operatorname{FBR}(t)$ is the fractional birth rate, and $\operatorname{PFP}(t)$ is the productive female population. The latter can in turn be defined as:

$\operatorname{PFP}(t)=\zeta \operatorname{POPW}(t)$

with the parameter $\zeta$ denoting the fraction of childbearing working age female population. The outflow BSA(t) (number of children entering the school age) is:

$\operatorname{BSA}(t)=\varepsilon \operatorname{POP}(I ; t)$

where $\varepsilon$ represents the fraction of infant population that turn six years old. And the outflow IDR $(t)$ (number of infants that die) amounts to:

$\operatorname{IDR}(t)=\operatorname{POP}(I ; t) \cdot \operatorname{FDR}(t)$

Analogous definitions hold for the other population cohorts. The school age population stock evolves over time as: 
$\operatorname{POP}(S ; t)=\operatorname{POP}(S ; t-d t)+\int[\operatorname{BSA}(t)-\operatorname{BWA}(t)-\operatorname{SDR}(t)] d t$

where $\operatorname{BSA}(t)$ is the inflow of children entering school age, $\operatorname{BWA}(t)$ the outflow of children entering working age, and $\operatorname{SDR}(t)$ the school age children that die. $\operatorname{BWA}(t)$ is further defined as:

$\operatorname{BWA}(t)=\eta \operatorname{POP}(S ; t)$

with $\eta$ the fraction of school age population that become adults and enter the working age. $\operatorname{SDR}(t)$ depends on the fractional death rate $\operatorname{FDR}(t)$ :

$\operatorname{SDR}(t)=\operatorname{POP}(S ; t) \cdot \operatorname{FDR}(t)$

Next, the working age population stock is:

$\operatorname{POPW}(t)=\operatorname{POPW}(t-d t)+\int[\mathrm{BWA}(t)-\mathrm{BE}(t)-\mathrm{WDR}(t)] d t$

which grows by the inflow of people newly entering the working age in the period (BWA $(t)$ ), and decreases by the outflows of population entering the elderly (pension) age, $\operatorname{BE}(t)$, plus those that die (WDR $(t))$. These two outflows can be further specified as:

$\mathrm{BE}(t)=\theta \operatorname{POPW}(t)$

where $\theta$ is the fraction of working age population entering the elderly (pension) age; and: 
$\operatorname{WDR}(t)=\operatorname{POPW}(t) \cdot \operatorname{FDR}(t)$

which is defined as the product of the fractional death rate $\operatorname{FDR}(t)$ and the working age population $\operatorname{POPW}(t)$. The latter is in turn a fraction $\mathrm{\iota}$ of the economically active working age population $\operatorname{POPW}^{\mathrm{A}}(t)$ :

$\operatorname{POPWA}^{\mathrm{A}}(t)=\iota \operatorname{POPW}(t)$

Finally, the stock of elderly population POPE also evolves as the sum of inflows and outflows:

$\operatorname{POPE}(t)=\operatorname{POPE}(t-d t)+\int[\mathrm{BE}(t)-\operatorname{EDR}(t)] d t$

The inflow is given by $\mathrm{BE}(t)$, the number of people that become elder every year (i.e. entering pension age); and the outflow is the number of elderly people that die, $\operatorname{EDR}(t)$, according to the elderly death rate $\operatorname{EDR}(t)$ :

$\operatorname{EDR}(t)=\operatorname{POPE}(t) \cdot \operatorname{FDR}(t)$

\subsection{Overview of the model: the causal loop diagram}

Figure 1 presents the causal loop diagram (CLD), which summarizes all main variables and relationships among them, indicating how these variables co-evolve over time. As noted in section 2.2, the CLD is composed of a set of nodes and edges: the former are the variables composing the system, and the latter are arrows representing the causal relationships among these variables (Barlas, 1996; Sterman, 2002). The CLD in figure 1 
highlights two different types of feedback loops: on the one hand, reinforcing loops (R) indicate the dynamics of two or more variables that sustain each other over time setting in motion a cumulative and self-reinforcing causation mechanism. On the other hand, balancing loops (B) point out a mechanism by which the growth of a variable is attenuated (hampered) by the growth of another variable, thus tending to report the system back to the initial equilibrium status. The dynamics of the economic system is governed by the set of reinforcing and balancing feedback loops among the main variables.

We first summarize the role of physical capital accumulation (sec. 3.1). Figure 1 points out two distinct mechanisms that link capital accumulation to the growth of GDP. The first is a direct effect: investments in firms' physical capital and public infrastructures increase the productivity of the supply-side of the economy (embodied technological progress). Specifically, the causal loop diagram shows two reinforcing feedback loops that drive the self-sustaining relationship between capital investment, on the one hand, and productivity and GDP growth, on the other: R1 (Government investment) and R9 (private sector investment). However, the process of physical capital accumulation is hampered by capital depreciation, which lowers the quality and efficiency of capital machineries and infrastructures as time goes by, as indicated by the balancing feedback loop B4. The second mechanism is indirect. Capital investments and infrastructure building in manufacturing and service industries grow relatively faster than capital accumulation in the agriculture sector, and so workers gradually shift from primary to secondary and tertiary branches. These industries will hence increase their labor shares and productivity levels. In figure 1, this structural change mechanism is visualized by the reinforcing loop R8 (attractiveness). 
Next, we summarize the role of the R\&D sector (sec. 3.2). The effect of R\&D activities on economic growth is direct. This is pointed by the two reinforcing feedback loops R4 and R5 (public and private $R \& D$ ), which indicate that $\mathrm{R} \& \mathrm{D}$ investments have an impact on the productivity of the supply-side of the economy, since innovation spurs firms' productivity. This does in turn foster GDP dynamics through the reinforcing feedback loops R1 and R9 described above. However, our model also introduces a lag between input and output of scientific and technological activities, reflecting the fact that $R \& D$ investments often take long time before having a visible and measurable impact in terms of scientific and technological output (see balancing loop B5). This slows down and partly counteracts the cumulative effect of innovation on productivity and GDP growth. Next, the effect of human capital accumulation on economic growth (sec. 3.3) is twofold. On the one hand, public investments in education and in the schooling system have a direct effect on the productivity of the supply-side of the economy, since workers that have completed tertiary education are more productive than non-skilled workers. This is highlighted by the reinforcing feedback loop R2 (public education), which is directly linked to goods and service production. On the other hand, human capital also has an indirect effect on economic growth through the role of the higher education system (and in particular PhD programs). This forms highly skilled workers that can be employed as researchers in public and private $R \& D$ activities. This second mechanism, linking up to feedback loops R4 and R5 noted above, does therefore point out an interaction mechanism between human capital accumulation and innovation (Howitt, 2000; Howitt and Mayer-Foulkes, 2005).

Finally, the role of the health sector and population dynamics (sec. 3.4) is visualized in the bottom part of figure 1 . The model points out two indirect effects of health investments on GDP growth, both linked to the reinforcing loop R5 (public health). One 
is that improving health infrastructures fosters the achievement of better health outcomes (fertility, mortality, life expectancy), hence increasing the size (and physical conditions) of the population that can be employed in productive activities. The second indirect effect is through education and human capital accumulation: a greater population size will also increase the size of the pool of educated workers to be employed in productive activities and in the R\&D sector. This mechanism does feature an interaction between health, population dynamics, human capital accumulation and R\&D. Notice that these interactions are also subject to various balancing feedback loops that tend to attenuate and hamper the growth process. In particular, balancing loop B1 (population control) points out that, as an economy grows and its population become wealthier, individuals will increasingly choose to have a smaller number of highly educated children, and this will decrease the country's fertility rate, thus counteracting the reinforcing loop R5 noted above (Galor and Weil, 2000; Galor, 2004).

In a nutshell, the model presents a view of economic growth as a complex coevolutionary process in which several growth engines interact with each other through a set of reinforcing and balancing feedback mechanisms. Specifically, any increase in GDP in a given period will make more resources available during the next period for both private sector investments as well as fiscal policies (infrastructures, public R\&D, education, health), and this will in turn foster further the growth of GDP through the set of direct and indirect relationships described in this section.

\section{$<$ Figure 1 here $>$}




\section{Simulation results and model's long-run properties}

\subsection{Simulating three distinct growth paths}

In the SD modelling methodology, the first typical phase of model validation and analysis is to carry out computer simulations to understand "why the model behaves the way it does" (Barlas, 1996), and the dynamic outcomes it leads to over time (Forrester, 1979; Sterman, 2002). This is the task we carry out in this section. In our model, the coevolutionary mechanisms studied in the previous section can generate a variety of distinct growth paths. As it will be shown below, the model's outcomes point out that developing economies can stagnate, grow slowly or catch up rapidly, depending on their initial conditions, structural characteristics and policy parameters.

To show this further, we have calibrated the model for three developing economies setting different values for four key policy parameters: the share of private sector GDP saved and reinvested in the domestic economy $(\pi)$; the annual rate of inward FDI $(p)$; public infrastructure investments as a share of Government expenditures ( $\varsigma$ ); and public $R \& D$ as a share of Government expenditures $(u)$. Table 1 reports the values of the main calibrated parameters. In this exercise, we assume that the growth disaster country has a low value for all these parameters, indicating a weak development policy effort; the middle-income trapped economy has intermediate levels of the policy parameters; and the growth miracle country has higher values, indicating a much more active policy effort to set in motion a rapid catch up process. As shown in table 1, for simplicity we assume in this simulation exercise that the three countries only differ with respect to these four policy parameters, but are otherwise similar in terms of their public 
education and health policies, industrial and population structure, and all other relevant characteristics. $^{9}$

\section{$<$ Table 1 here >}

Figure 2 shows the time path for the main outcome variables of the model for a 200 -year period. ${ }^{10}$ The main outcome variables that we report to document and compare the dynamic performance of these three economies are: GDP per capita (GDPPC), population (POP), innovative capability (IC), labor productivity (LP), inward FDI (FDI), and net exports (EXP).

The first panel of figure 2 shows how the GDP per capita dynamics differs among these three developing economies. The growth disaster country does not experience any visible improvement in its income per capita level over time. The middle-income trapped economy grows steadily and slowly, but its transitional dynamics process is long and does not enable to catch up with advanced countries at the frontier. By contrast, the growth miracle country grows rapidly following a logistic trend and completes its catch up process by reaching its steady state level after around 75 years.

The other panels in figure 2 illustrate in further details the working of the model and the factors that generate these income dynamics paths. For all three countries, the total population (and the economically active working age population alike) declines slowly over time as a result of a demographic transition process. After an initial increase due to

\footnotetext{
${ }^{9}$ Initial values of all variables and most relevant parameters have been calibrated by setting them at an average value of the group of middle-income countries (developing economies) according to the clustering exercise presented by Castellacci (2011). The source of the data is World Bank's World Development Indicators. The calibration for the variables and parameters not reported in table 1 are available upon requests.

${ }^{10} \mathrm{After} \mathrm{t}=200$, the model converges to a steady state, and there is no significant change to report. This is the reason why figure 2 only reports time paths until $t=200$.
} 
growing public health investments, population declines in the long-run as a result of decreasing fertility rates. The diminishing population size constrains the supply-side of the economy by reducing the pool of educated workers employed in production and R\&D activities.

This negative trend, however, leads to different outcomes for the three economies we simulate here, depending on the strength of the various reinforcing feedback loops that were previously described in section 3.5. In the growth disaster country, the innovative capability and labor productivity will stagnate and remain fairly stable in the long-run, and the external sector of the economy will as a consequence also experience a negative performance (very low inflow of FDI and a constant trade balance deficit). The middleincome trapped economy is only partly able to counteract the decreasing population trend: R\&D investments and the productivity of the supply-side of the economy will slowly increase, leading to a gradual improvement in inward FDI and export performance. However, this capability building process is rather slow leading to a long transitional dynamics period and hence an overall slow development and unsuccessful catch up process. Finally, the growth miracle country is the one that is able to achieve rapid growth and catch up by means of a dynamic R\&D sector, vibrant supply-side productivity growth and positive performance of the external sector of the economy (trade and FDI). This rapid catch up process is generated by the interaction between the main reinforcing feedback loops summarized in section 3.5, and particularly those related to physical capital investments (private and public) and $R \& D$ investments (which are precisely the policy parameters that differ among the three countries in this experiment).

In short, the model generates developing economies that tend to multiple steady states, depending on countries' structural characteristics and the related policy parameters. 
This outcome resembles that generated by previous multiple equilibria models, but the present result is obtained through a different approach. In this model, it is the interaction among several different growth factors that explains countries' aggregate performance in the long-run. Economies that are able to activate and support synergies among the various reinforcing feedback mechanisms can achieve a faster catch up process and more sustained income per capita level in the long-run than countries characterized by weaker co-evolutionary dynamics.

\section{$<$ Figure 2 here >}

\subsection{Long-run properties of the model}

A second typical phase of model validation and analysis in the SD modelling approach is to carry out simulations to perform a policy analysis, in which the analyst studies the extent to which model's outcomes vary if different policy actions will be introduced (e.g. the "changed-behavior-prediction" test; see Forrester, 1979; Barlas, 1996). Our policy analysis has carried out two sets of simulation exercises to investigate the long-run properties of the model, and specifically the extent to which the model's outcomes vary if we change the key policy parameters.

Specifically, the first set of experiments studies the effect on GDP per capita growth of changing one single policy parameter at a time (keeping all other parameters unchanged). This bivariate analysis intends to compare the impacts of different development policies that countries can implement in order to set up a catch up process. We have focused on the six policy parameters of the model (those noted in table 1 above). For each of them, we have run 100 simulations, setting 100 different values for the policy parameter between a minimum and a maximum level within its definition 
domain. We have then recorded the final level of GDP per capita at the end of each simulation run. Figure 3 shows the results of this bivariate analysis. Each panel of the figure plots the final level of GDP per capita for each of the 100 simulations run for a given policy parameter. The results can be summarized by grouping these parameters and the related plots in two different categories.

On the one hand, for the three parameters related to physical capital accumulation private domestic investments, FDI and public infrastructures - increasing policy efforts lead to sustained income growth: investment and infrastructure policies make it possible to achieve a high level of income per capita at the end of the period. As noted in the summary provided in section 3.5, these factors play a pivotal role for the dynamics of the economic system as direct drivers or primary engines of economic growth.

On the other hand, the other three policy parameters considered in figure 3 - public health, public education and R\&D policy - are characterized by different long-run properties. Increasing public policy efforts in these domains tend to lead relatively quickly to a saturation (ceiling) point, meaning that policy efforts to increase these variables beyond a certain level will not lead to any visible increase in the long-run GDP per capita level. In other words, these factors alone are not sufficient to achieve fast catch up and sustained growth in the long-run, but they are important indirect drivers or enabling factors, i.e. necessary preconditions for catch up.

\section{$<$ Figure 3 here >}

In the second exercise, we simulate the effects of different policy combinations on the level of GDP per capita during the transitional dynamics and on its long-run steady state. This multivariate analysis is carried out by focusing on the three policy parameters that 
have the strongest effect on income per capita (according to the results previously presented in figure 2), and running a battery of simulations with different combinations of these parameters. Specifically, we have assigned to each policy parameter two different values in its definition domain (low and high), yielding eight distinct combinations or policy scenarios. Table 2 presents the results of these simulations reporting the level of GDP per capita during the transitional dynamics $(t=30)$ and in the longer term $(t=100)$ for each policy scenario.

The results indicate that if only one single policy is implemented (corresponding to the exercises presented in figure 2 above), supporting domestic private capital investments is the most effective strategy (even more than attracting FDI). The reason for this is the central importance assumed in our model by physical capital accumulation as primary growth engine, since it fosters a process of structural change, and at the same time sustains the growth of industrial productivity. On the other hand, R\&D policy acts as an enabling factor or indirect growth engine, leading to growth during the transitional dynamics, but it is not sufficient to catch up in the long-run.

If two policy changes are implemented simultaneously, table 2 shows that the most effective combination is public R\&D coupled with domestic private capital accumulation. This combination does not only lead to a high final level of income per capita in the longrun $(t=100)$, but also a rapid catch up process in the shorter-term $(t=30)$. Finally, the last row of table 2 shows that if all three policies are implemented together, there is a slight increase in GDP per capita compared to the previous cases in the short-run, but no substantial increase in the steady state level of income per capita at $t=100$. This result is arguably explained by the fact that some of the most important equations in our model, and in particular those describing productivity dynamics, are governed by logistic functional forms in which growth faces in the long-term decreasing returns and 
hampering factors that slow down its long-run dynamics. These limits are structural and exogenously imposed in our model (e.g. defined by scientific, technological and efficiency frontiers that no country is able to overcome at a given time in history). Hence, in our model, an active combination of different development policies can enable a rapid process of transitional dynamics and catching up, but it will not be able to overcome such structural and historically contingent limits to growth.

In short, the simulation results indicate that the optimal policy mix is a combination of high domestic investments in physical capital (the direct driver of the growth process) and public R\&D (an enabling condition that permits those capital investments to achieve high productivity). This combination leads to synergies and multiplicative effects that generate co-evolutionary self-sustained growth and a rapid catch up process.

\section{$<$ Table 2 here $>$}

\section{Conclusions}

The paper has presented a new modeling approach for the study of co-evolutionary economic growth. Recent multiple equilibria models explain convergence clubs and nonlinearities as the result of threshold externalities and the interactions between some major growth factors: human capital, innovation, industrial structure, and/or population dynamics. Extending this literature, the present work has developed a model that represents economic growth as a complex process in which all of these factors - rather than only one or few of them - simultaneously interact with each other, generating coevolutionary growth of the economic system.

We have represented this co-evolutionary growth process by means of a system dynamics model, which by its own nature focuses on feedback mechanisms and co- 
evolutionary dynamics among a set of interrelated dimensions. By means of simulation analysis, we have studied the long-run properties of the model. The model generates developing economies that converge to different steady states, depending on countries' structural characteristics and the related set of policy parameters. This growth heterogeneity pattern, with national economies converging to different steady states, resembles the typical outcome generated by multiple equilibria models (such as Galor and Moav; Howitt and Mayer-Foulkes, 2005; Hausman and Hidalgo, 2011). However, the new point highlighted in this paper is that it is the interaction among different growth factors that explains countries' aggregate performance in the long-run, and hence crosscountry growth heterogeneity. Economies that are able to activate and support synergies among the various reinforcing feedback mechanisms can achieve a faster catch up process and more sustained income per capita level in the long-run than countries characterized by weak co-evolutionary dynamics.

The simulation results also indicate that the optimal policy mix for developing economies is a combination of high domestic investments in physical capital (the direct driver of the growth process) and R\&D policy (an enabling condition that permits those capital investments to achieve high productivity). This combination leads to synergies and multiplicative effects that generate co-evolutionary self-sustained growth and a rapid catch up process.

On the whole, the contribution of this work is to propose SD modelling as a brand new approach to study co-evolutionary economic growth. The main advantage of this modelling approach is its comprehensiveness, i.e. its endeavor to study growth as a complex process driven by the co-evolution of a multiplicity of variables. This will potentially lead to several applications and extensions in the future, e.g. by including 
additional relevant factors, such as institutions, financial development, social and geographical factors.

However, the use of system dynamics modelling in growth theory does also present some potential issues and costs that it is important to consider. One of them, in particular, is the lack of analytical tractability of this type of complex nonlinear dynamic models. The price to pay for achieving a greater realism and more comprehensive description of the development process is the increasing complexity of the model, and the need to resort to the use of simulation analysis, rather than steady state analytical solutions, in order to explore the model's properties. It is therefore of paramount importance that this type of modelling exercise and simulation analysis makes an effort to present the model's properties in an open and detailed manner, so that the reader can get a thorough understanding of the specific mechanisms that generate a given result.

\section{References}

Abatecola, G. (2012): "Interpreting corporate crises: Towards a co-evolutionary approach", Futures, 44 (10): 860-869.

Aghion, P. and Howitt, P. (1992): "A model of growth through creative destruction", Econometrica 60: 323-351.

Barlas, Y. (1996): "Formal aspects of model validity and validation in system dynamics", System Dynamics Review, 12 (3): 183-210.

Booth Sweeney, L. and Meadows, D. (2010): The Systems Thinking Playbook: Exercises to Stretch and Build Learning and Systems Thinking Capabilities, Chelsea Green Publishing.

Benhabib, J. and Spiegel, M. (1994): "The role of human capital in economic development. Evidence from aggregate cross-country data", Journal of Monetary Economics, 34: 143-173.

Carlaw, K. and Lipsey, R. (2006): “GPT-driven endogenous growth”, Economic Journal, 116: $155-174$.

Castellacci, F. (2004): "A neo-Schumpeterian Approach to Why Growth Rates Differ", Revue économique, 55(6): 1145-1169. 
Castellacci, F. (2010): "Structural change and the growth of industrial sectors: Empirical test of a GPT model", Review of Income and Wealth, 56(3): 449-482.

Castellacci, F. (2011): “Closing the technology gap?”, Review of Development Economics, 15 (1): 180-197.

Castellacci, F. and Natera, J.M. (2013): "The dynamics of national innovation systems: a panel cointegration analysis of the co-evolution between innovative capability and absorptive capacity", Research Policy, 42 (3): 579-594.

Castellacci, F. and Hamza, K. (2015): "Policy Strategies for Economic Development in Cuba: A Simulation Model Analysis"; NUPI Working Paper.

Feng, M., Liu, P., Li, Z., Zhang, J., Liu, D., and Xiong, L. (2016): "Modeling the nexus across water supply, power generation and environment systems using the system dynamics approach: Hehuang Region, China", Journal of Hydrology, 543: 344-359.

Forrester, J. W. (1961): Industrial Dynamics, Cambridge, MIT Press.

Forrester, J. (1979): “Tests for building confidence in system dynamics models”, D-29267, Sloan School of Management, MIT, Cambridge.

Galor, O. (2005), "From Stagnation to Growth: Unified Growth Theory", in: Aghion, Ph. and S. Durlauf (eds.), Handbook of Economic Growth, Elsevier, North Holland.

Galor, O. and O. Moav (2000): "Ability-Based Technological Transition, Wage Inequality, and Economic Growth", Quarterly Journal of Economics, 115: 469-497.

Galor, O. and D.N. Weil (2000): "Population, Technology, And Growth, From Malthusian Stagnation To The Demographic Transition And Beyond", American Economic Review, 90: 806-828.

García-Cabrera, A., Durán-Herrera, J. (2016): "MNEs as institutional entrepreneurs: A dynamic model of the co-evolutionary process", European Management Journal, 34 (5): 550-563.

Geels, F.W. (2006): "Co-evolutionary and multi-level dynamics in transitions: The transformation of aviation systems and the shift from propeller to turbojet (19301970)", Technovation, 26 (9): 999-1016.

Growieca, K. and Growieca, J. (2014): "Social capital, trust, and multiple equilibria in economic performance”, Macroeconomic Dynamics, 18(2): 282-315.

Hacklin, F., Marxt, C. and Fahrni, F. (2009): “Co-evolutionary cycles of convergence: An extrapolation from the ICT industry", Technological Forecasting and Social Change, 76 (6): 723-736. 
Hausman, R. and C. Hidalgo (2011): "The network structure of economic output", Journal of Economic Growth, 16: 309-342.

Howitt, P. (2000): "Endogenous Growth and Cross-Country Income Differences", American Economic Review 90: 829-846.

Howitt, P. and D. Mayer-Foulkes (2005), "R\&D, Implementation and Stagnation: A Schumpeterian Theory of Convergence Clubs", Journal of Money, Credit and Banking, 37: 147-177.

Hynes, N. and Wilson, J. (2012): "Co-evolutionary dynamics in strategic alliances: The influence of the industry lifecycle", Technological Forecasting and Social Change, 79 (6): 1169-1175.

Kelly, M. (2001): "Linkages, Thresholds, and Development", Journal of Economic Growth, 6: 39-53.

Lucas, R. (1988): "On the mechanics of economic development" Journal of Monetary Economics, 22: 3-42.

Luo, S., Du, Y., Liu, P., Xuan, Z. and Wang, Y. (2015): “A study on co-evolutionary dynamics of knowledge diffusion and social network structure", Expert Systems with Applications, 42 (7): 3619-3633.

Nelson, R. and Winter, S. (1982): An Evolutionary Theory of Economic Change, Cambridge: The Belknap Press of Harvard University Press.

Quitzow, R. (2015): "Dynamics of a policy-driven market: The co-evolution of technological innovation systems for solar photovoltaics in China and Germany", Environmental Innovation and Societal Transitions, 17: 126-148.

Reid, G.C. and Smith, J.A. (2009): “A co-evolutionary analysis of organisational systems and processes: Quantitative applications to information system dynamicsin small entrepreneurial firms", Critical Perspectives on Accounting, 20 (6): 762-781.

Ríos-Núñez, S., Coq-Huelva, D. and García-Trujillo, R. (2013): “The Spanish livestock model: A co-evolutionary analysis", Ecological Economics, 93: 342-350.

Robinson, D. (2009): “Co-evolutionary scenarios: An application to prospecting futures of the responsible development of nanotechnology", Technological Forecasting and Social Change, 76 (9): 1222-1239.

Romer, P. (1990): “Endogenous technological change”, Journal of Political Economy, 98: S71-S102.

Solow, R. (1956): "A contribution to the theory of economic growth", Quarterly Journal of Economics, 70: 65-94. 
Sotarauta, M. and Srinivas, S. (2006): "Co-evolutionary policy processes: Understanding innovative economies and future resilience", Futures, 38 (3): 312-336.

Sterman, J. (2002): "System dynamics: system thinking and modeling for a complex world”, ESD-WP-2003-01.13, MIT Sloan School of Management.

Tsai, F., Hsieh, L., Fang, S. and Lin, J. (2009): "The co-evolution of business incubation and national innovation systems in Taiwan", Technological Forecasting and Social Change, 76 (5): 629-643.

Winder, N., McIntosh, B. and Jeffrey, P. (2005): “The origin, diagnostic attributes and practical application of co-evolutionary theory", Ecological Economics, 54 (4): 347-361.

Windrum, P. and Birchenhall, C. (1998): "Is product life cycle theory a special case? Dominant designs and the emergence of market niches through co-evolutionarylearning", Structural Change and Economic Dynamics, 9 (1): 109-134.

Wong, C. (2009): "Rent-seeking, industrial policies and national innovation systems in Southeast Asian economies”, Technology in Society, 33 (3-4): 231-243.

Zagler, M. and Durnecker, G. (2003): "Fiscal policy and economic growth", Journal of Economic Surveys, 17(3): 397-4. 
Figure 1: Causal loop diagram (CLD): overview of the main feedback loops in the model

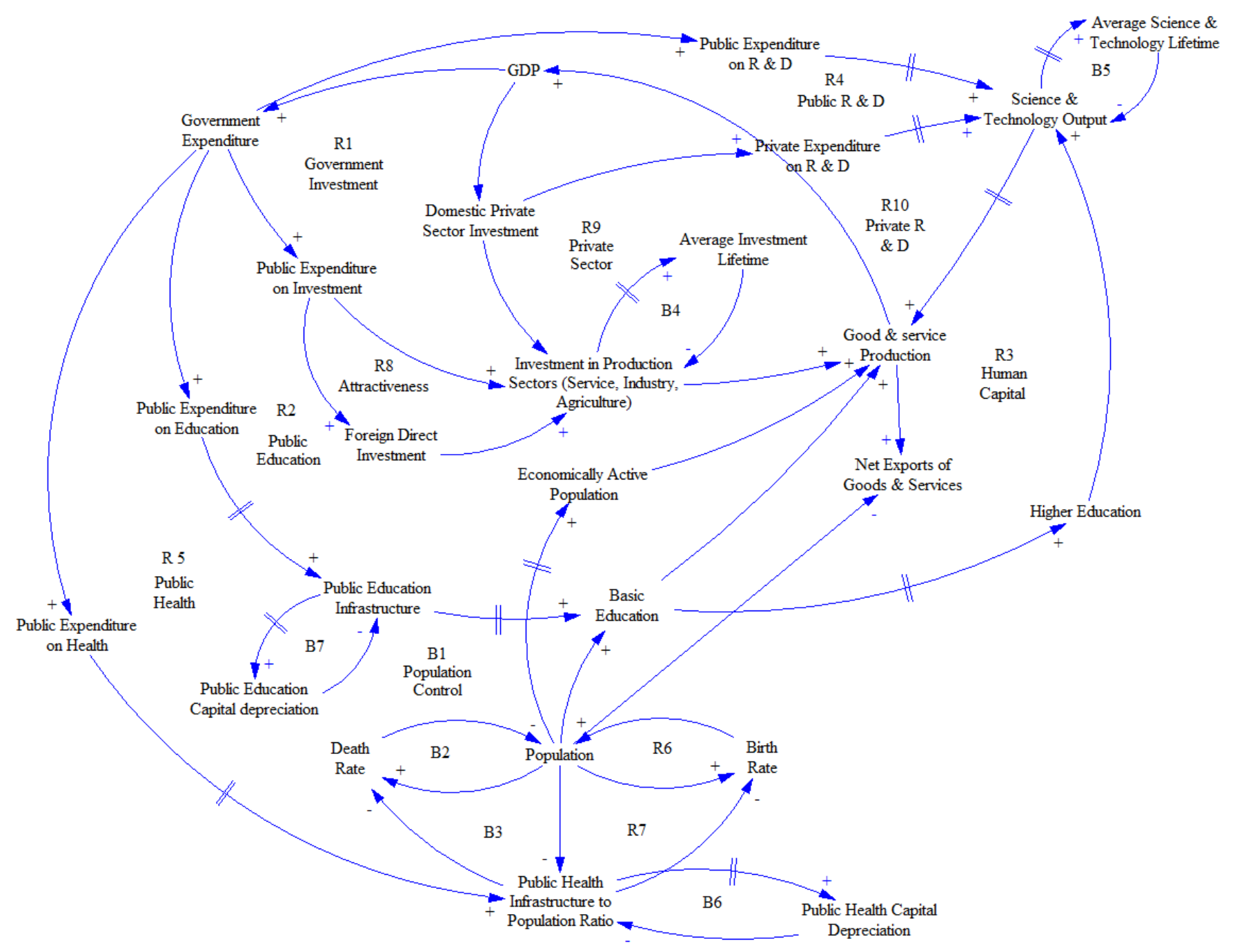


Table 1: Model calibration for three developing economies

\begin{tabular}{|c|c|c|c|}
\hline & Growth disaster (1) & $\begin{array}{l}\text { Middle-income } \\
\text { trapped (2) }\end{array}$ & Growth miracle (3) \\
\hline \multicolumn{4}{|l|}{ Policy parameters* } \\
\hline Private sector GDP reinvested $(\pi)$ & $1 \%$ & $5 \%$ & $10 \%$ \\
\hline Annual FDI rate (b) & $1 \%$ & $5 \%$ & $10 \%$ \\
\hline Public investments ( $\mathrm{\varsigma}$ ) & $10 \%$ & $15 \%$ & $20 \%$ \\
\hline Public R\&D (v) & $0.50 \%$ & $0.75 \%$ & $1 \%$ \\
\hline Public education ( $\kappa)$ & $15 \%$ & $15 \%$ & $15 \%$ \\
\hline Public health $(\alpha)$ & $15 \%$ & $15 \%$ & $15 \%$ \\
\hline \multicolumn{4}{|l|}{ Industry labor shares* } \\
\hline Agriculture & $19 \%$ & $19 \%$ & $19 \%$ \\
\hline Industry & $18 \%$ & $18 \%$ & $18 \%$ \\
\hline Services & $63 \%$ & $63 \%$ & $63 \%$ \\
\hline \multicolumn{4}{|l|}{ Industry value added shares* } \\
\hline Agriculture & $5 \%$ & $5 \%$ & $5 \%$ \\
\hline Industry & $21 \%$ & $21 \%$ & $21 \%$ \\
\hline Services & $74 \%$ & $74 \%$ & $74 \%$ \\
\hline \multicolumn{4}{|l|}{ Population* } \\
\hline $0-14$ years old & $18 \%$ & $18 \%$ & $18 \%$ \\
\hline $15-64$ years old & $70 \%$ & $70 \%$ & $70 \%$ \\
\hline 65 - above & $12 \%$ & $12 \%$ & $12 \%$ \\
\hline Death rate & $0.7 \%$ & $0.7 \%$ & $0.7 \%$ \\
\hline Birth rate & $3 \%$ & $3 \%$ & $3 \%$ \\
\hline Life expectancy & 79 & 79 & 79 \\
\hline \multicolumn{4}{|l|}{ Time lags (years) } \\
\hline Lag scientific investments - output & 10 & 10 & 10 \\
\hline Lag technological investments - output & 10 & 10 & 10 \\
\hline Lag scientific output - innov. capability & 10 & 10 & 10 \\
\hline Lag technol. output - innov. capability & 10 & 10 & 10 \\
\hline Investment lifetime: Private capital & 20 & 20 & 20 \\
\hline Investment lifetime: FDI & 20 & 20 & 20 \\
\hline Investment lifetime: Public capital & 20 & 20 & 20 \\
\hline
\end{tabular}

Source: World Bank, World Development Indicators 
Figure 2: Simulating time trends for three developing countries: growth disaster (1), middle-income trapped (2), growth miracle (3)

GDP per capita

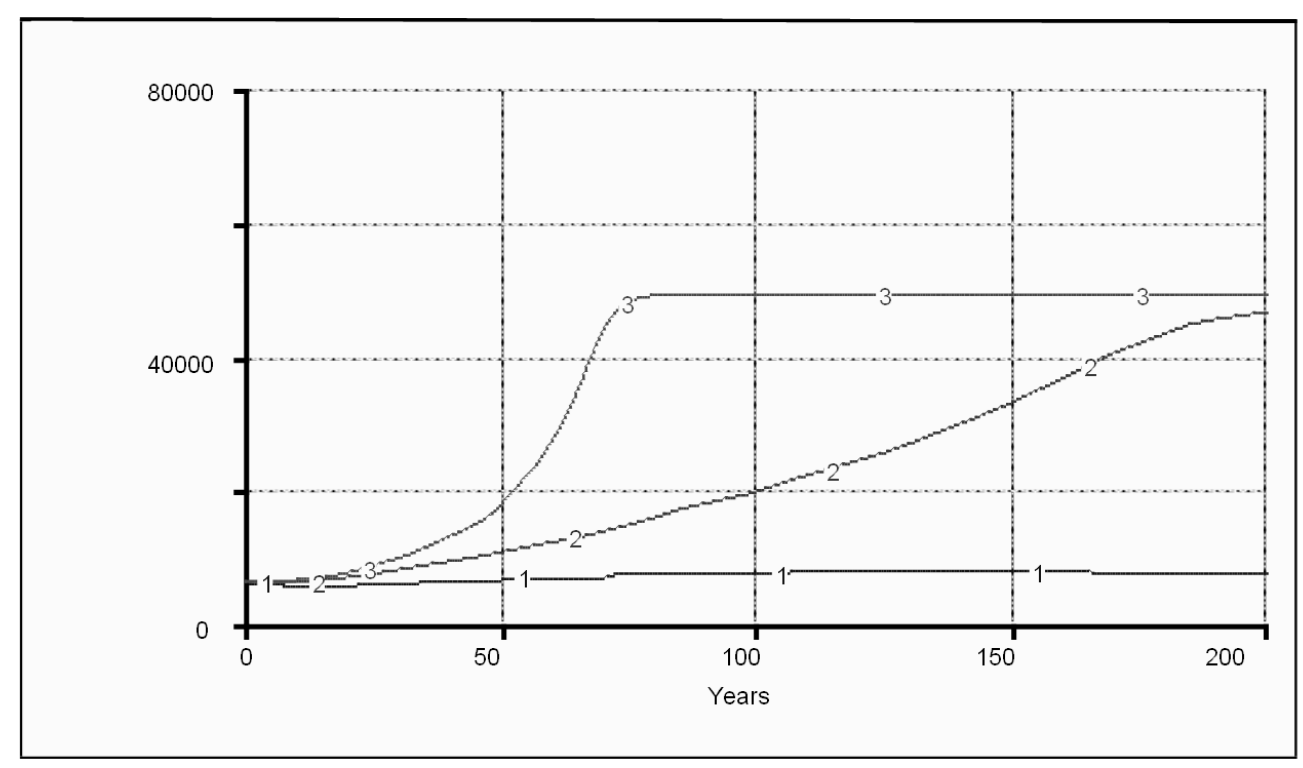

Population

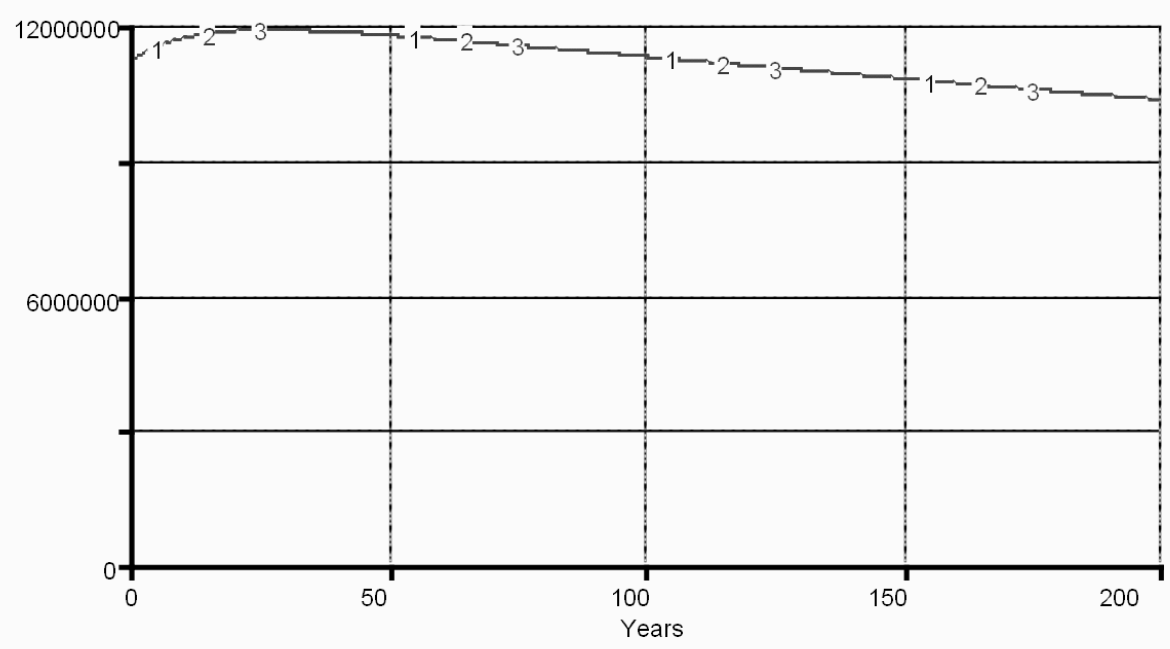


Innovative capability

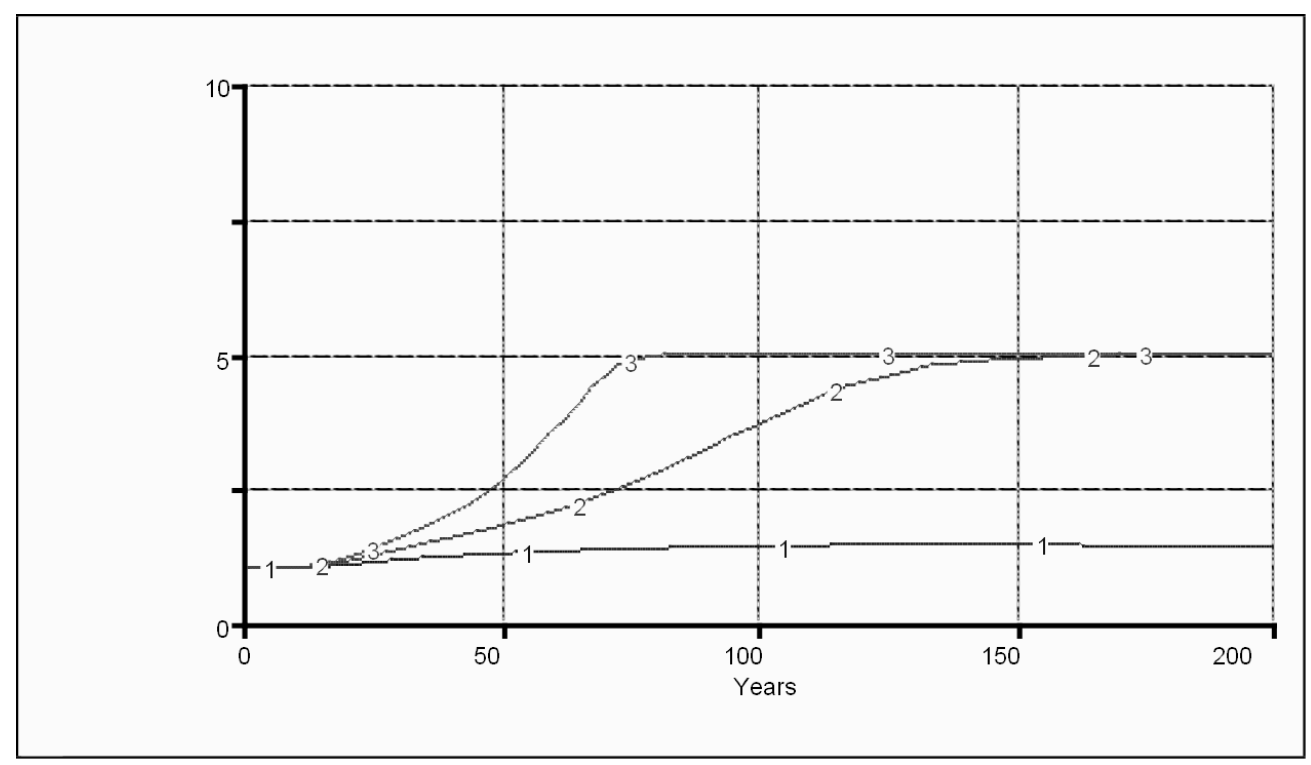

Labor productivity

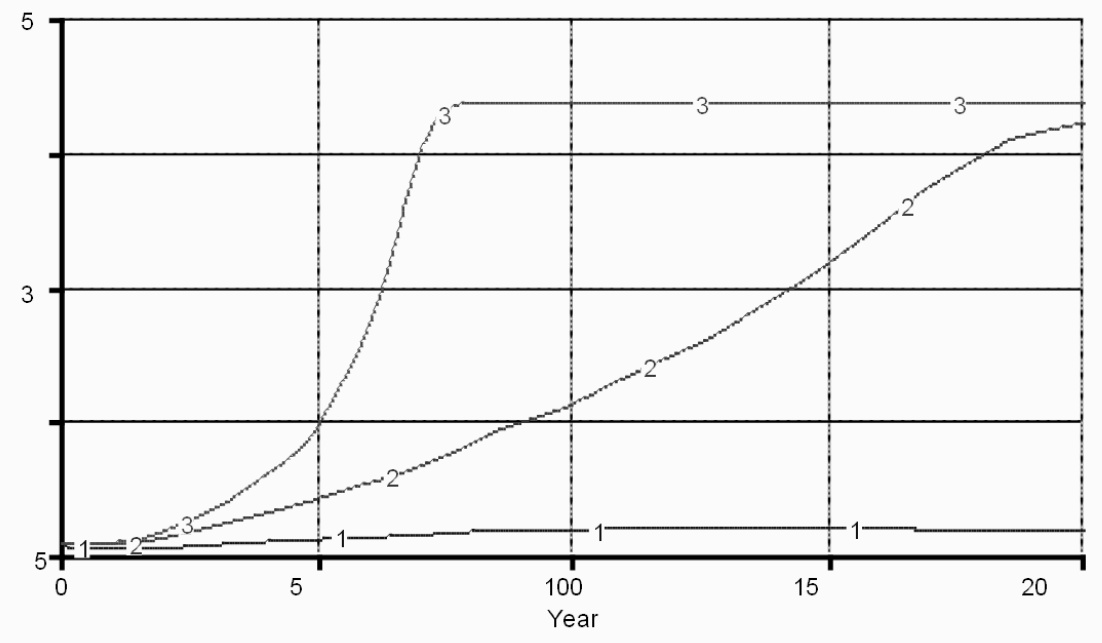


Inward FDI

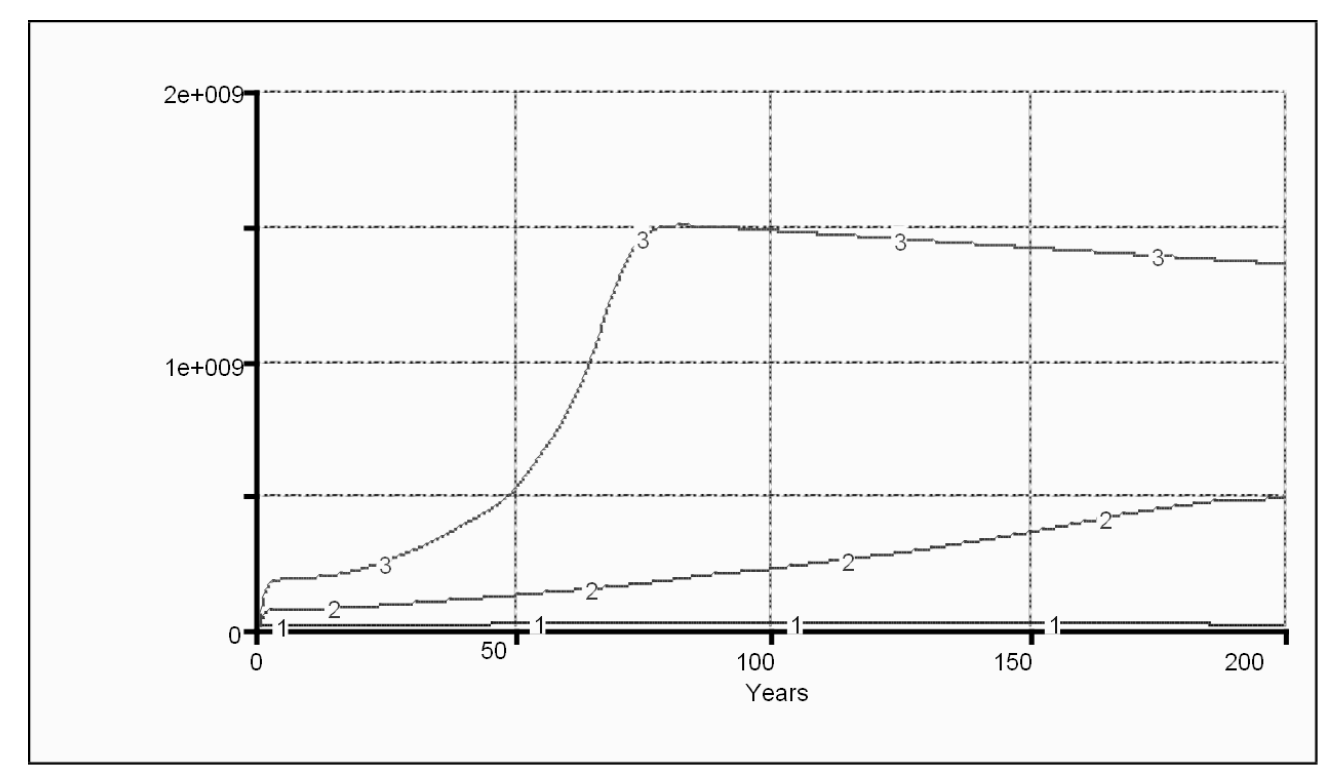

Net exports

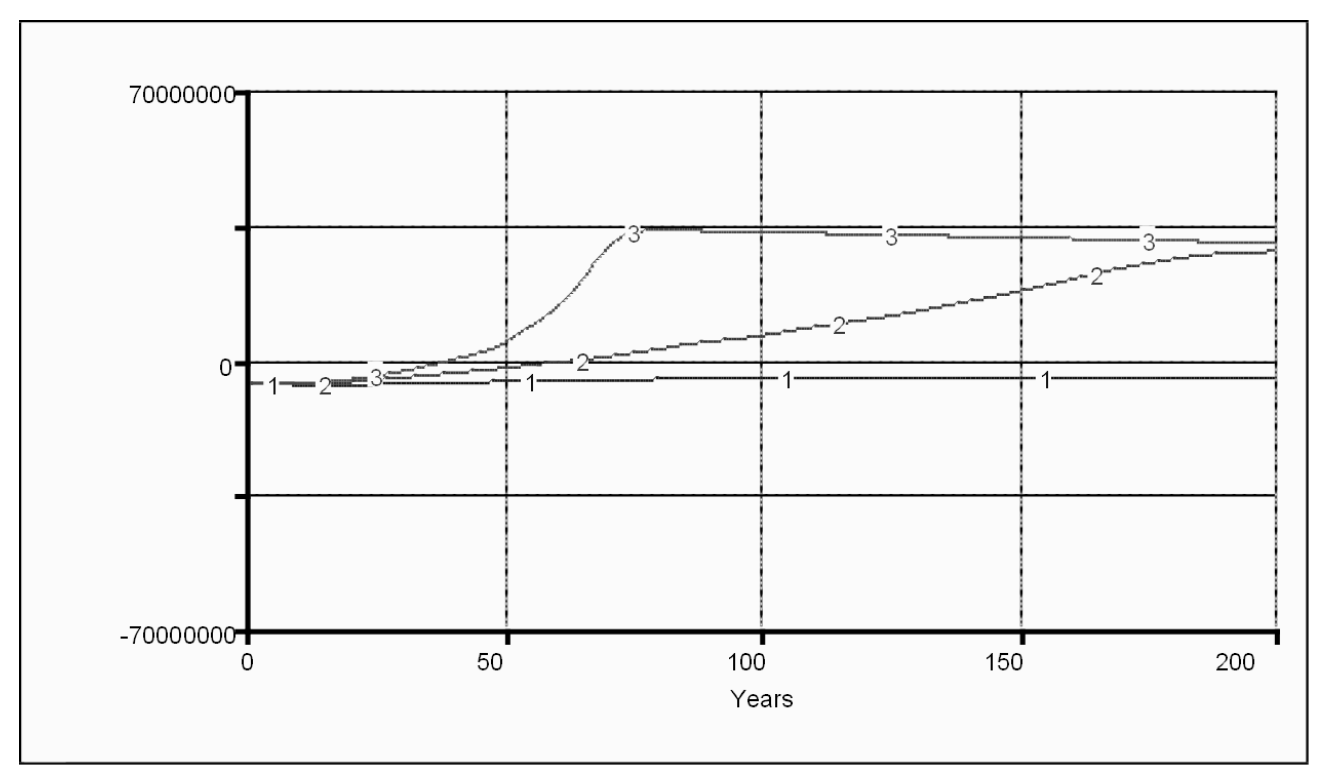


Figure 3: Long-run properties: Effects of policy changes (bivariate analysis)
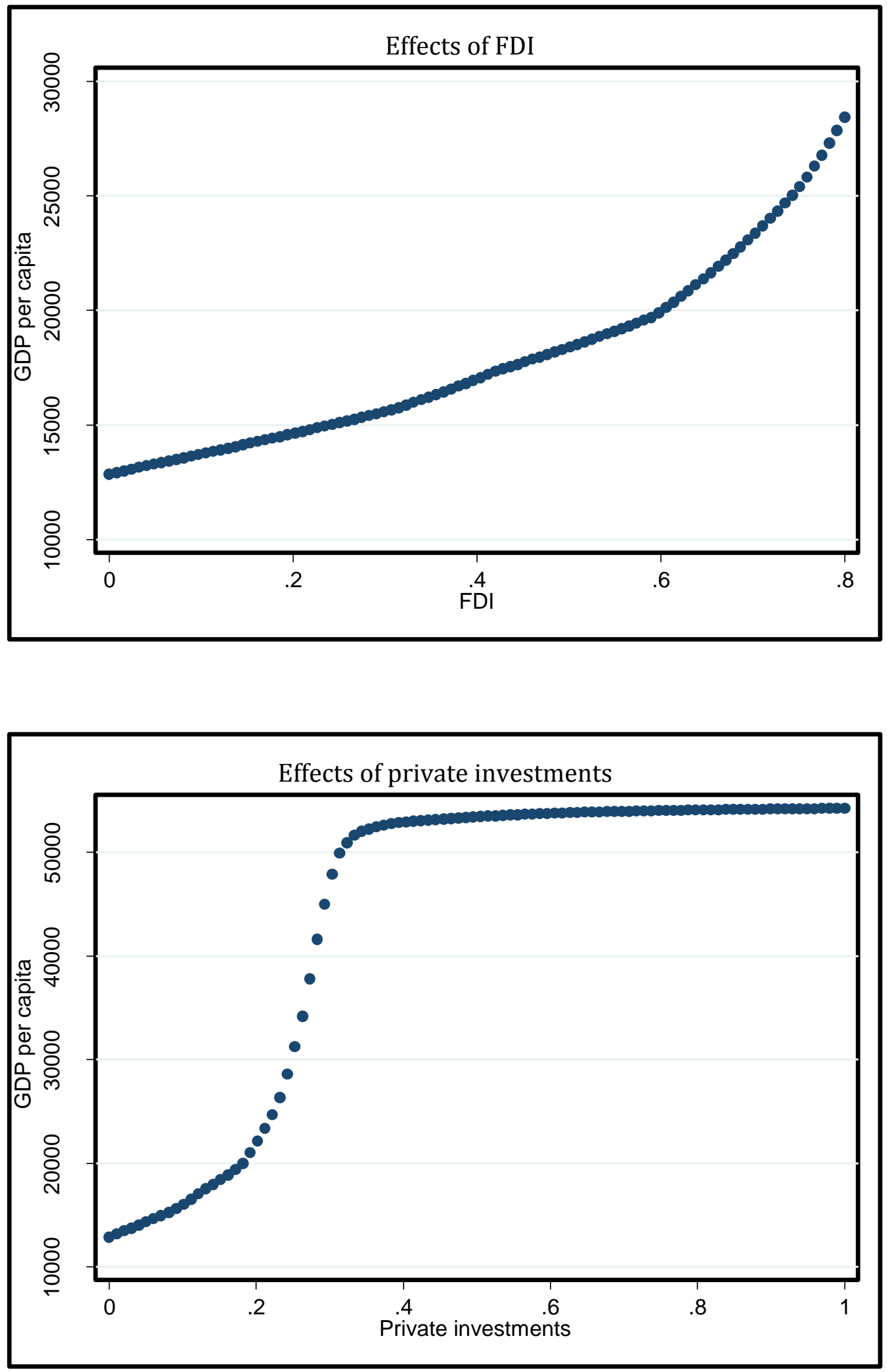

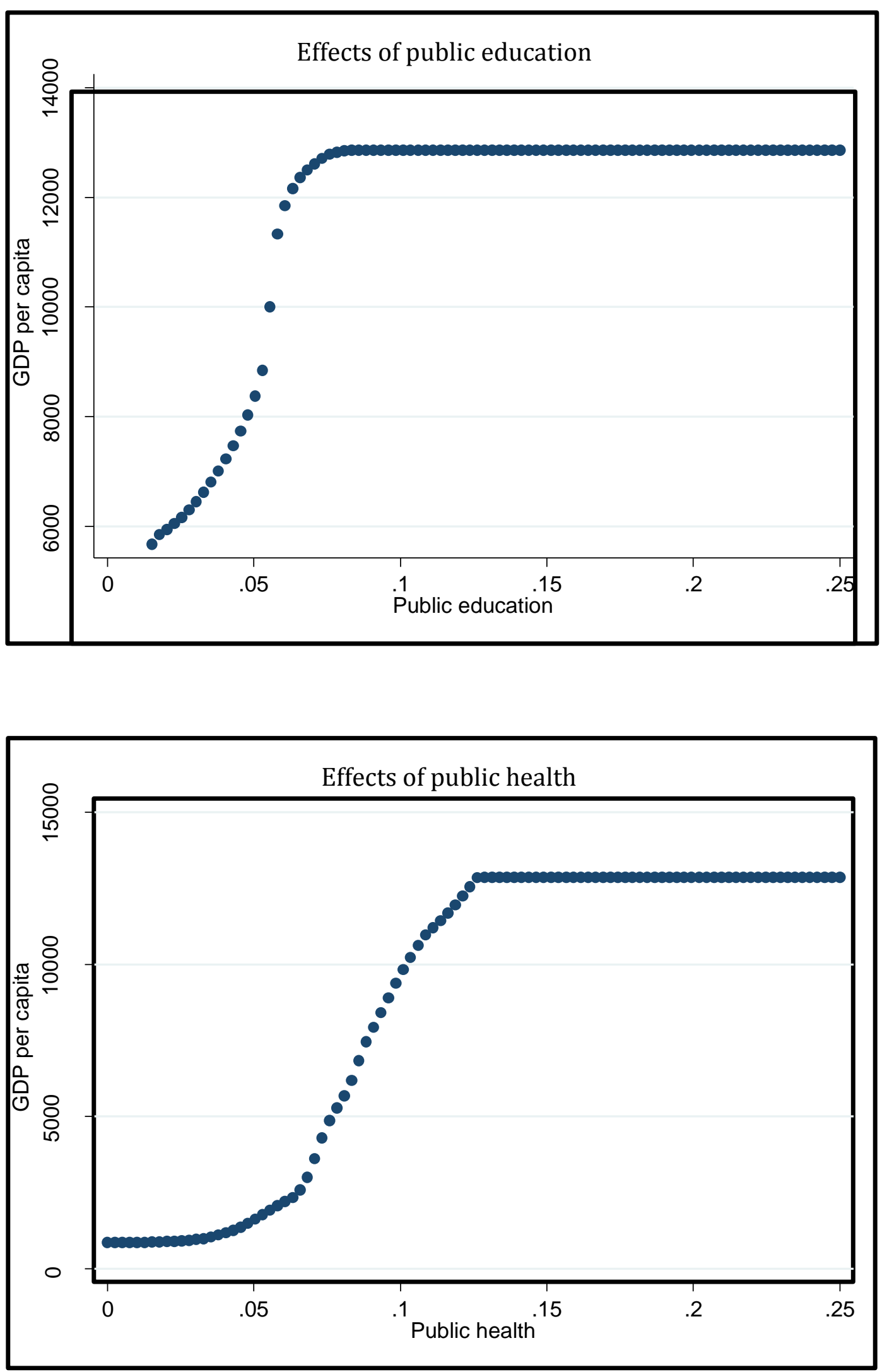

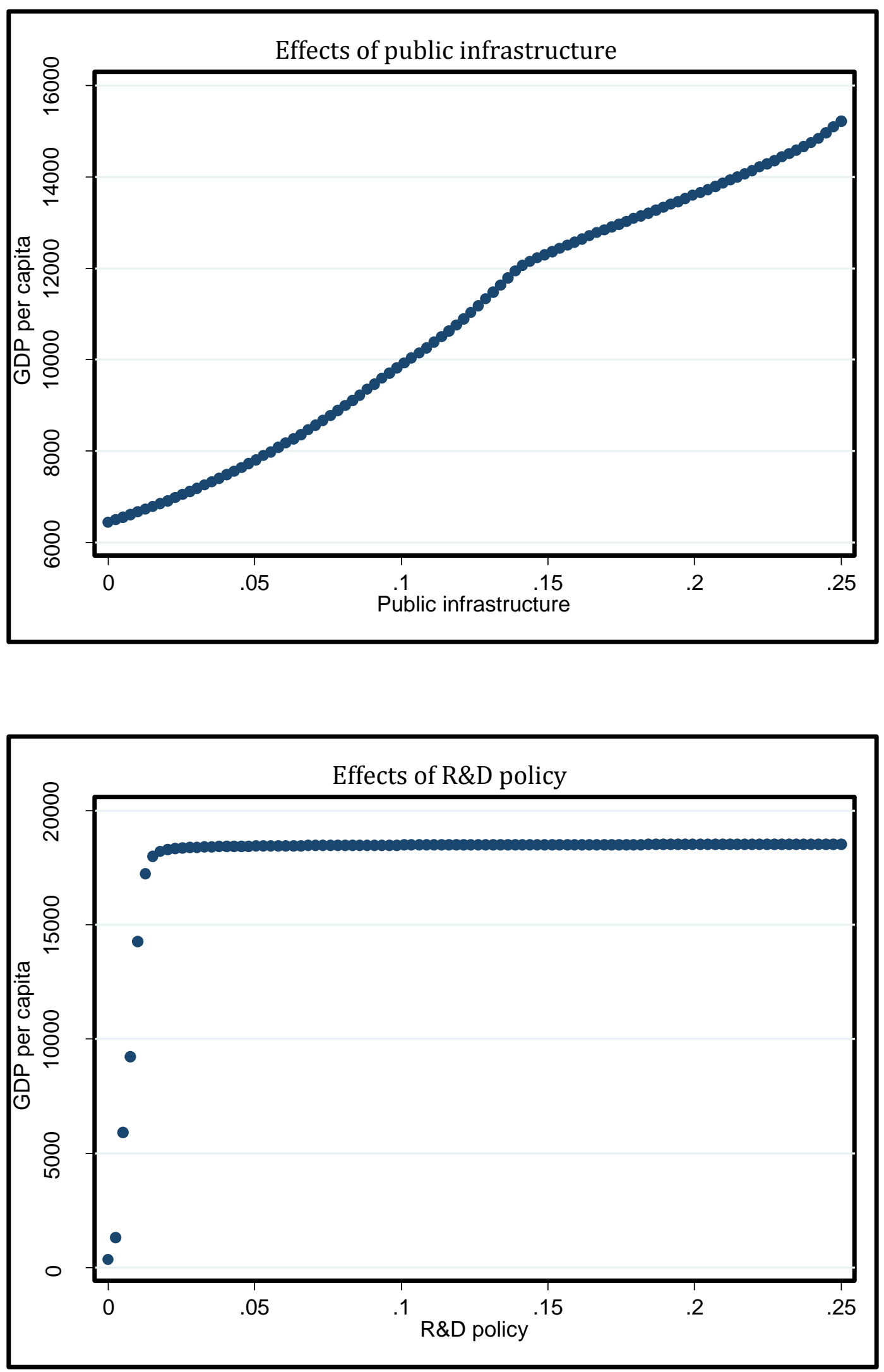
Table 2: Optimal catch up policy: Effects of different policy combinations (multivariate analysis)

\begin{tabular}{|ccccc|}
\hline $\begin{array}{c}\text { Private } \\
\text { investments }\end{array}$ & Inward FDI & Public R\&D & $\begin{array}{c}\text { GDP per capita } \\
(\boldsymbol{t}=\mathbf{3 0})\end{array}$ & $\begin{array}{c}\text { GDP per capita } \\
(\boldsymbol{t}=\mathbf{1 0 0})\end{array}$ \\
Low & Low & Low & 8309 & 13233 \\
Low & Low & High & 18114 & 18903 \\
Low & High & Low & 10119 & 49744 \\
High & Low & Low & 28055 & 54243 \\
Low & High & High & 29574 & 52853 \\
High & High & Low & 31345 & 54375 \\
High & Low & High & 53684 & \\
\hline High & High & High & 54244 \\
\hline
\end{tabular}

Legend: Each policy parameter takes two values: low and high. The values are defined as follows. Private investments: 1\% (Low); 100\% (High); Inward FDI: 1\% (Low); 100\% (High); Public R\&D: 1\% (Low); 5\% (High). 


\section{Appendix: List of parameters and variables}

\section{Variables (endogenous)}

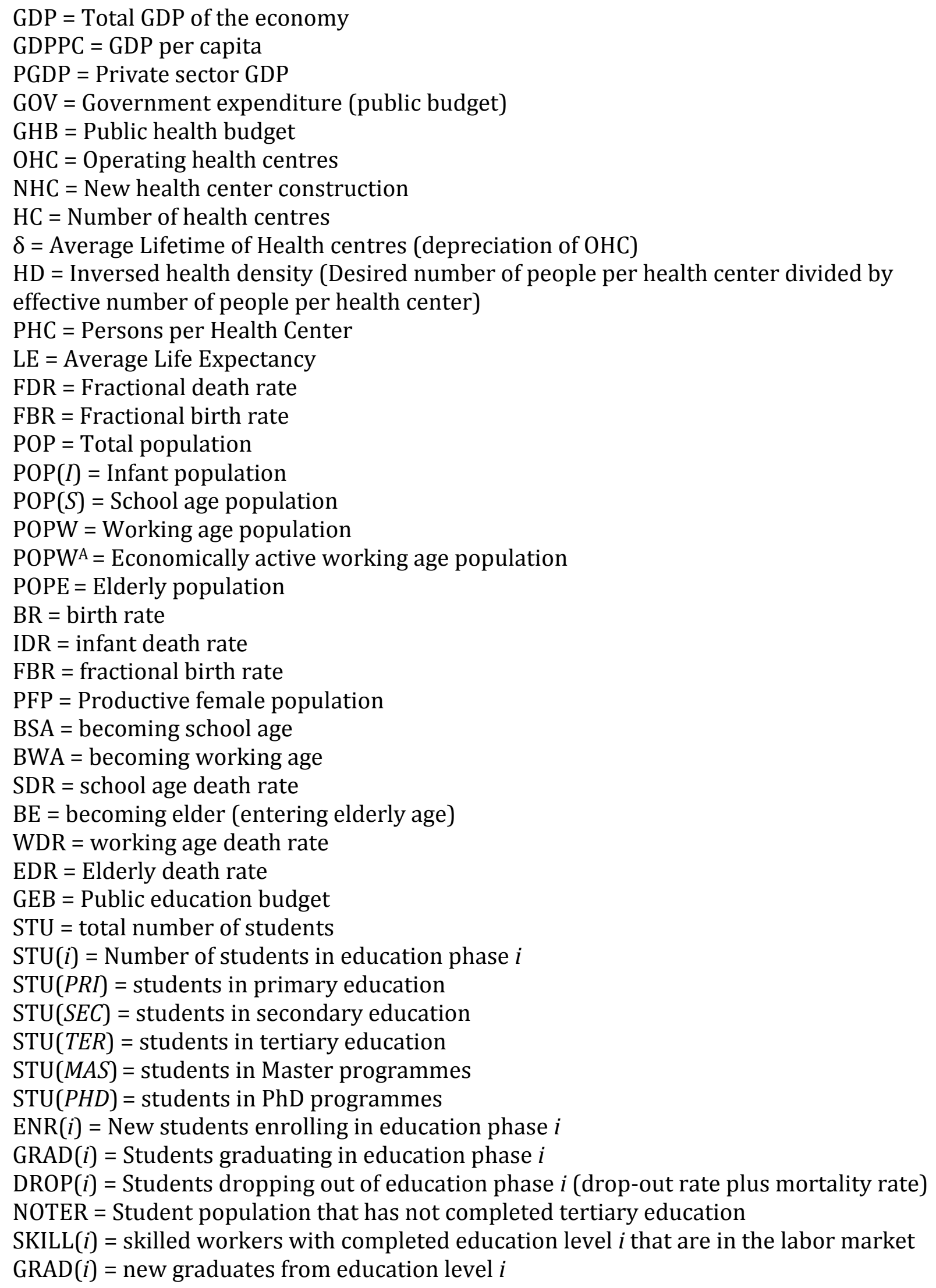


$\operatorname{ENR}(i+1)=$ skilled workers with education level $i$ that decides to enroll in more advanced education level $i+1$

$\operatorname{RET}(i)=$ skilled workers with education level $i$ that retire

WDR $=$ skilled workers with education level $i$ that die

$\mathrm{EDU}=$ Ratio between the number of persons with a tertiary degree and the total population workforce

$\mathrm{PK}=$ Private sector physical capital

FDI = Inward foreign direct investments

$\Pi(j)=$ industry's $j$ share of GDP

GINV = Public sector investments in physical capital (public infrastructures)

$\mathrm{K}(j)=$ Total capital (infrastructures) invested in each industry

$\operatorname{ATTR}(j)=$ Attractiveness of sector $j$ (determinant of labor mobility across sectors)

$\mathrm{L}(j)=$ Labor employed in sector $j$

$\mathrm{LS}(j)=$ Labor share of sector $j$

$\mathrm{LP}(j)=$ Labor productivity of sector $j$

$\operatorname{GDP}(j)=$ GDP produced in sector $j$

$\operatorname{EXP}(j)=$ Net export of sector $j$

$\mathrm{C}(j)=$ domestic consumption of goods produced by sector $j$

GR\&D = Public R\&D investments

$\mathrm{GR} \& \mathrm{D}(j)=$ Public R\&D investments in sector $j$

GPHD $=$ PhD graduates employed in public sector research

GPHD $(j)=$ PhD graduates employed in public sector research in field $j$

$\operatorname{SOP}(j)=$ Scientific output productivity (productivity of public research sector) in each

field $j$

$\mathrm{SO}(j)=$ Scientific output in field (sector) $j$

PR\&D $(j)=$ Private R\&D investments in sector $j$

$P R \& D=$ Total private R\&D investments in the country

$\mathrm{PPHD}=\mathrm{PhD}$ graduates employed in private sector research

PPHD $(j)=$ PhD graduates employed in private sector research in field $j$

TOP $(j)=$ Technological output productivity (productivity of private research sector) in field $j$

$\mathrm{TO}(j)=$ Technological output in field (sector) $j$

$\operatorname{IC}(j)=$ Innovative capability sector $j$

$\operatorname{STR}(j)=$ Ratio of science to technological output in sector $j$

STR = Ratio of science to technological output in the whole economy

\section{Parameters (exogenous)}

$\Omega=$ Private sector share of GDP

$\Psi=$ Public sector share of GDP

$\alpha=$ Percent of GOV assigned to public health

$\beta=$ Operational costs per health center (per year)

$\gamma=$ Initial Costs to Build Health Center

$\gamma=$ max decrease in depreciation rate due to higher government health expenditures

PHC* ${ }^{*}$ Desired number of people per health center

$\mathrm{a}=$ max increase in average life expectancy as an effect of improving health

infrastructures

$\mathrm{b}=$ slope of effect of health conditions on mortality rate 
$\mathrm{c}=$ slope of effect of improved health service on fertility

$\zeta=$ Fraction of childbearing working age female population

$\varepsilon=$ fraction of infant population entering school age (i.e. turning six years old)

$\eta=$ fraction of school age population entering working age

$\theta=$ fraction of working age population entering elderly (pension) age

$\mathrm{\imath}=$ portion of economically active working age population

$\kappa=$ Percent of GOV assigned to Public education

$\lambda=$ Investment required per student

$\mu(i)=$ enrollment rate of population in education phase $i\left(\mathrm{POP}_{i}\right)$

$v(i)=$ graduation rate of students enrolled in education phase $i\left(\mathrm{POP}_{i}\right)$

$\xi(i)=$ drop-out and mortality rate of students enrolled in education phase $i\left(\mathrm{POP}_{i}\right)$

$\mathrm{o}(i)=$ retirement rate for skilled workers with completed education level $i$ (SKILL $i$ )

$\pi=$ Portion of private sector GDP reinvested in the economy

$\rho=$ Average lifetime of capital (depreciation of PK and FDI)

$\mathrm{p}=$ Annual FDI Rate: Share of FDI on total GDP of the economy

$\varsigma=$ Percent of GOV expenditure assigned to public capital (infrastructure) investments

$\sigma(i)=$ Share of PINV allocated to sector $j$

$s=$ Time required for attractiveness level to affect labor share

$\tau(i)=$ fraction of GDP per capita consumed by each individual to purchase goods

produced by sector $j$

$v=$ Percent of GOV expenditure assigned to public R\&D (public science investments)

$\varphi(i)=$ Share of GR\&D allocated to sector $j$

$\psi=$ costs to hire a $\mathrm{PhD}$ employee in the public sector

$\omega=$ retirement rate $\omega$

$\ddot{v}(j)=$ Fraction of publicly employed $\mathrm{PhD}$ that works in field $j$

$r=$ lag between R\&D investments and scientific and technological output

$\chi=$ Average lifetime of scientific output

$\Theta(j)=$ Share of private sector GDP allocated to R\&D in sector $j$

$\Gamma=$ costs to hire a $\mathrm{PhD}$ employee in the private sector

$\Lambda(j)=$ Fraction of publicly employed PhD that works in field $j$

$\Phi=$ patents per scientific publication (i.e. parameter indicating the effects of scientific on

technological output)

$\Xi=$ Average lifetime of scientific output (depreciation of TO)

$\mathrm{g}=$ max increase in innovative capability due to an increase in scientific capability

$\mathrm{h}=$ max increase in innovative capability due to an increase in technological capability 